Merci d'utiliser le titre suivant lorsque vous citez ce document :

Czaga, P. (2004-11-16), « Analyse des mesures non tarifaires : Les interdictions et contingentements à l'importation », Éditions OCDE, Paris. http://dx.doi.org/10.1787/542752152740

\title{
Analyse des mesures non tarifaires
}

\section{LES INTERDICTIONS ET CONTINGENTEMENTS À L'IMPORTATION}

Peter Czaga

La version originale de ce document a été publiée comme suit :

Czaga, P. (2004-09-27), "Analysis of Non-Tariff Measures: The Case of Prohibitions and Quotas", OECD Trade Policy Papers, No. 6, OECD Publishing, Paris. http://dx.doi.org/10.1787/650468803072 
Organisation de Coopération et de Développement Economiques

Organisation for Economic Co-operation and Development

16-Nov-2004

DIRECTION DES ECHANGES

Français - Or. Anglais

COMITE DES ECHANGES

Groupe de travail du Comité des échanges

ANALYSE DES MESURES NON TARIFAIRES : LES INTERDICTIONS ET CONTINGENTEMENTS À L'IMPORTATION

Document de travail de l'OCDE sur la politique commercial no 6

Peter Czaga

Les documents de travail sur la politique commerciale sont maintenant disponibles sur le site Internet de l'OCDE : http//www.oecd.org/trade 


\begin{abstract}
RÉSUMÉ
La présente étude, qui porte sur deux formes particulières de restrictions quantitatives, à savoir les interdictions d'importation et les contingents, s'inscrit dans le cadre d'une réflexion plus ample visant à mieux cerner la nature et la portée des mesures non tarifaires. Elle examine les informations relatives à ces mesures contenues dans les Examens des politiques commerciales de l'OMC, les notifications à l'OMC et divers autres rapports sur les échanges. Elle a pour objectif d'apporter sa contribution aux débats, notamment ceux concernant l'accès au marché des produits non agricoles, à l'OMC ou dans d'autres instances. L'étude a révélé que le recours aux contingents et aux prohibitions est moins souvent motivé par des raisons économiques, mais que la plupart des pays intègrent des interdictions à leurs cadres réglementaires afin de protéger la santé et la sécurité humaine ou l'environnement, tendance qui semble s'accentuer. Les négociants tireraient avantage de mesures plus transparentes à cet égard. Par ailleurs, il existe des interdictions d'importation qui entravent le commerce international des biens usagés et dont les particularités et la pertinence en termes d'efficacité réglementaire mériteraient d'être examinée de plus près.
\end{abstract}

Mots-clés : mesures non tarifaires, restrictions quantitatives, prohibitions, contingents, biens usagés.

\title{
REMERCIEMENTS
}

La présente étude a été rédigée par Peter Czaga, de la Direction des échanges, en collaboration avec Barbara Fliess et sous la supervision d'Anthony Kleitz. Elle a été examinée par le Groupe de travail du Comité des échanges, qui a décidé d'en diffuser plus largement les conclusions en procédant à sa déclassification sous la responsabilité du Secrétaire général. Elle est disponible en anglais et en français sur le site de l'OCDE, à l'adresse suivante : http://www.oecd.org/trade

Droits d'auteur : OCDE 2004

Les demandes de reproduction ou de traduction totales ou partielles de cette publication doivent être adressées à :

Services des Publications, OCDE

2, rue André-Pascal, 75775 PARIS CEDEX 16, France 


\section{TABLE DES MATIÈRES}

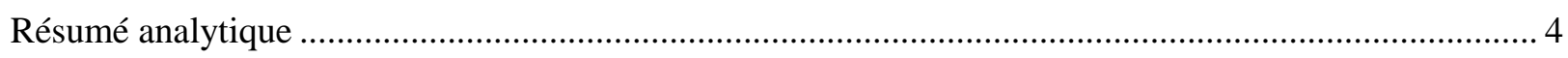

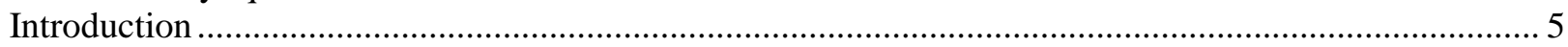

Définitions des mesures et observations relatives à la méthodologie..................................................... 5

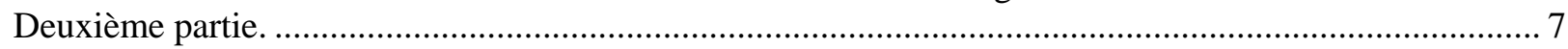

Panorama des disciplines de l'OMC relatives aux restrictions quantitatives .......................................... 7

Traitement des restrictions quantitatives dans les accords commerciaux régionaux (ACR) ….............. 8

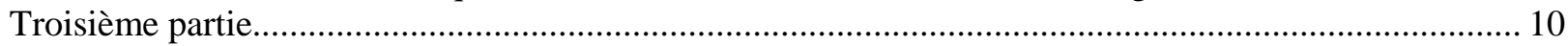

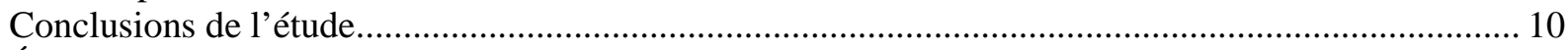

Études existantes portant sur l'incidence des restrictions quantitatives ............................................ 11

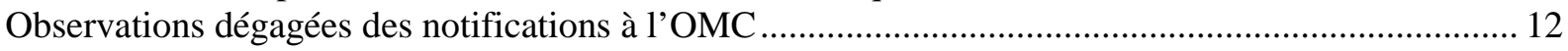

Questions relatives aux restrictions quantitatives dans le cadre du processus de règlement des

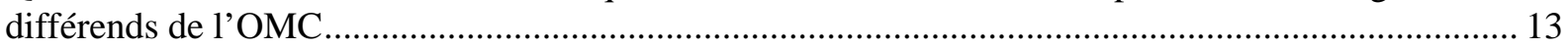

Le recours aux prohibitions et contingents pour des raisons économiques ......................................... 14

Restrictions appliquées à des fins de balance des paiements .............................................................. 14

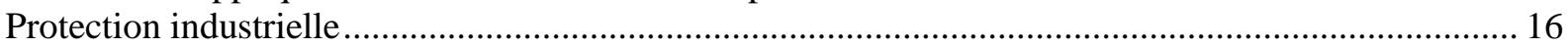

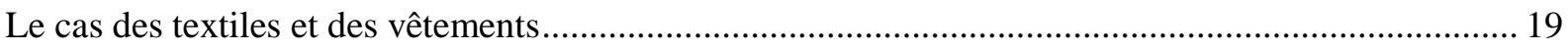

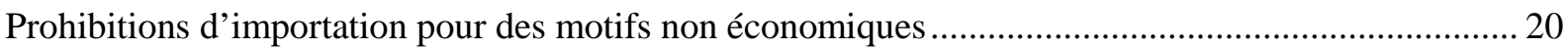

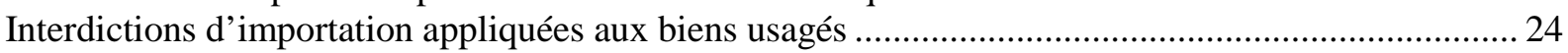

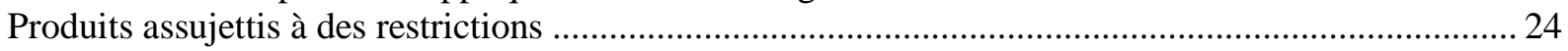

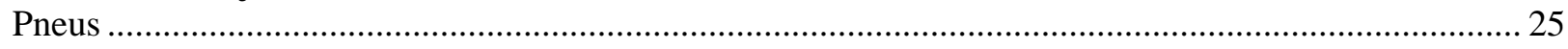

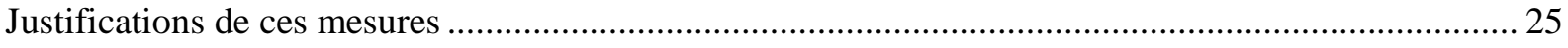

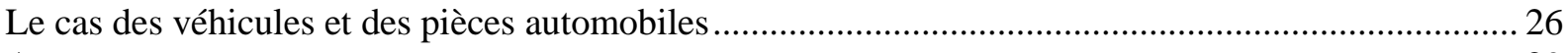

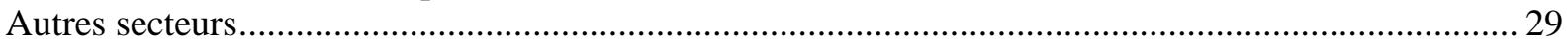

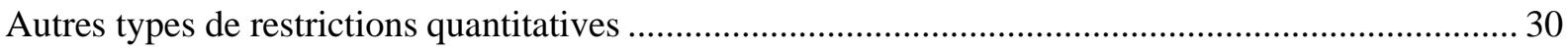

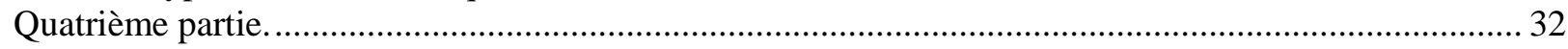

Conséquences économiques et commerciales des restrictions quantitatives ........................................ 32

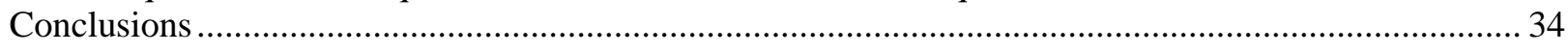

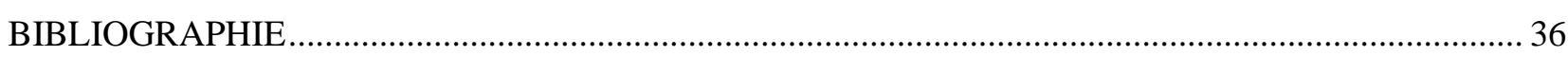

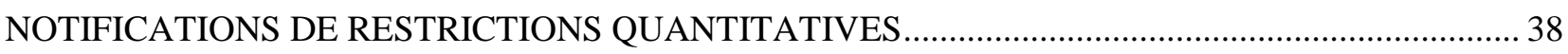

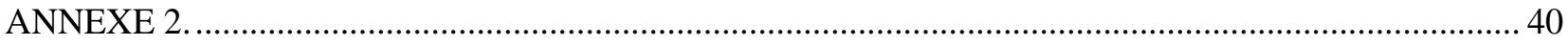

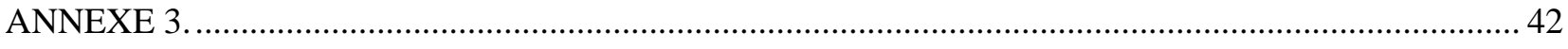

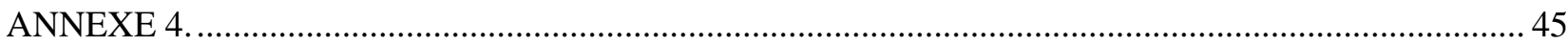




\section{ANALYSES DES MESURES NON TARIFAIRES : LES INTERDICTIONS ET LES CONTINGENTEMENTS A L'EXPORTATION}

\section{Résumé analytique}

Le présent rapport analyse deux sortes de restrictions quantitatives aux importations, les prohibitions et les contingents, dans le cadre du projet en cours du Comité des échanges dont l'objet est d'étudier les profils d'utilisation et les effets des diverses mesures non tarifaires. Les prohibitions sont généralement des interdictions d'importation absolues, tandis que les contingents limitent l'importation de produits particuliers en fixant une quantité ou une valeur maximale pour les marchandises dont l'importation est autorisée.

L'analyse présentée ici porte sur les informations disponibles sur ces mesures et contenues dans les Examens des politiques commerciales de l'OMC, les notifications à l'OMC, et divers autres rapports sur les échanges. Manifestement, le degré de transparence des systèmes de restrictions quantitatives est faible en comparaison à de nombreux autres domaines du régime commercial qui relèvent désormais de disciplines multilatérales. Aussi serait-il utile de trouver le moyen de renforcer les règles et la mise en œuvre du système de notification de l'OMC dans ce domaine.

Une tendance générale à la baisse peut être observée dans l'application de contingents et de prohibitions instaurés pour des motifs économiques, à cause de difficultés de la balance des paiements et en vue de protéger certains secteurs dans les pays en développement. Parallèlement, des interdictions établies pour des motifs non économiques, notamment afin de protéger l'environnement ainsi que la sécurité et la santé des personnes, sont appliquées dans pratiquement tous les pays et, semble-t-il, de plus en plus nombreuses. L'incidence de ces mesures semble augmenter plus rapidement dans les pays développés, qui possèdent généralement une réglementation sociale plus rigoureuse.

Les interdictions jouent un rôle particulièrement important dans les échanges de biens de consommation et d'équipement usagés. Elles portent en particulier sur l'importation de véhicules, de pièces automobile et de machines d'occasion, ainsi que de vêtements usagés, entre pays en développement et pays développés. Les circonstances qui motivent ces interdictions semblent parfois obscures et, en soulevant certaines questions de fond, mettent en lumière un domaine qui mériterait peut-être d'être analysé plus en détail et éventuellement pris en compte dans le cadre des négociations sur l'accès aux marchés des produits non agricoles.

Lorsqu'elle est appliquée pour des motifs non économiques, une interdiction d'importation est l'option retenue pour faire en sorte que divers objectifs réglementaires de nature sociétale soient atteints. Il importe de reconnaître la souveraineté réglementaire des pays, leur droit à fixer et à poursuivre des objectifs réglementaires qui leur sont propres. Dans le même temps, il faut que les pays tiennent compte des principes de qualité de la réglementation qui sont élaborés et prônés par l'OCDE. Dans le cas des interdictions, les autorités nationales doivent minutieusement déterminer si elles constituent la solution réglementaire optimale ou s'il en existe d'autres qui permettraient d'atteindre l'objectif réglementaire avec un effet de distorsion moins important pour l'économie et les autres objectifs sociétaux. 
TD/TC/WP(2004)28/FINAL

\section{Introduction}

1. Le présent document étudie l'utilisation et les effets sur les échanges de deux types spécifiques de restrictions quantitatives à l'importation : les prohibitions et les contingents. Il vient à l'appui de travaux précédents qui concernaient les licences d'importation non automatiques [TD/TC/WP(2002)39/FINAL] et les restrictions quantitatives à l'exportation [TD/TC/WP(2003)7/FINAL]. Les travaux actuels contribuent à une analyse plus complète des restrictions quantitatives aux échanges, et ont pour objet de fournir des informations générales supplémentaires utiles pour les discussions relatives aux mesures non tarifaires du Groupe de négociation sur l'accès aux marchés pour les produits non agricoles.

2. Le Cycle d'Uruguay a remis en avant l'objectif poursuivi par le GATT qui était de discipliner l'utilisation des restrictions quantitatives aux échanges, et s'est conclu avec des résultats significatifs. Les règles qui permettent l'application de ces restrictions dans certains cas ont été rendues plus rigoureuses, par exemple les restrictions appliquées pour des motifs liés à la balance des paiements, et les Membres de l'OMC ont été contraints de supprimer progressivement les mesures qui différaient de ces nouvelles règles. Malgré cette évolution, de nombreux Membres de l'OMC qui ont notifié des mesures non tarifaires au Groupe de négociation sur l'accès aux marchés pour les produits non agricoles, dans le cadre du mandat du PDD pour les négociations visant à réduire encore ou à éliminer les droits de douane et à s'attaquer aux mesures non tarifaires, mentionnent des « restrictions quantitatives ». De même, divers rapports nationaux ou du secteur privé sur les obstacles au commerce font état de plaintes concernant des mesures qui entrent dans la catégorie générale des restrictions quantitatives à l'importation. Cela signifie que les restrictions quantitatives, notamment les prohibitions et les contingents, demeurent une source de préoccupation pour les négociants et les gouvernements et ont des répercussions sur les relations commerciales internationales. En parallèle, on note un manque d'informations quant à la nature et à la fréquence de ces mesures. Dans ce contexte, la présente étude vise à mieux comprendre l'utilisation des prohibitions et des contingents ainsi que leurs retombées commerciales et économiques.

3. L'étude s'articule en quatre parties : la première définit les mesures qui sont examinées en détail et aborde quelques questions de méthodologie. La deuxième replace l'étude dans le contexte du système commercial multilatéral, en présentant les disciplines et les règles existantes du GATT/OMC qui régissent l'application de restrictions quantitatives à l'importation. Elle comprend également quelques exemples de la façon dont les prohibitions et les contingents sont traités dans de grands accords commerciaux régionaux et bilatéraux. La troisième résume les conclusions des études menées sur les répercussions de ces deux types de restriction à l'importation, ainsi que sur leur rôle et leurs profils d'utilisation. Dans la mesure où les interdictions jouent un rôle important dans les échanges internationaux de biens de consommation et d'équipement d'occasion, une section est consacrée à l'examen détaillé de cette question. Enfin, la quatrième partie analyse l'incidence commerciale et économique des prohibitions et des contingents sur le plan conceptuel et présente des données quantitatives issues des recherches effectuées dans ce domaine

\section{Première partie}

\section{Définitions des mesures et observations relatives à la méthodologie}

4. Selon la terminologie de l'OMC, les prohibitions et les contingents, de même que d'autres restrictions quantitatives à l'importation, sont des mesures appliquées à la frontière et qui ont un effet direct sur les importations. Ils ont pour objectif explicite soit de limiter le volume de produits importés particuliers entrant sur le marché national, soit d'interdire complètement leur importation. ${ }^{1}$

\footnotetext{
${ }^{1}$ Walter Goode, Dictionary of Trade Policy Terms, WTO et Cambridge University Press, 2003.
} 
- Les prohibitions sont des interdictions absolues d'importation. Elles peuvent parfois contenir des dispositions fixant les conditions dans lesquelles les marchandises sont autorisées à entrer dans le pays.

- Contingents - ils restreignent l'importation de produits donnés en fixant un volume ou une valeur maximale aux marchandises dont l'importation est autorisée. Il existe différents types de contingents: contingents mondiaux, bilatéraux, saisonniers, contingents associés aux résultats d'exportation, à l'achat de marchandises locales, contingents portant sur des catégories de produits sensibles, et contingents pour des motifs politiques.

5. Les analyses spécialisées soulignent à quel point il est difficile de mesurer les retombées commerciales et économiques réelles des restrictions quantitatives. La présente étude applique une méthode similaire à celle employée lors de recherches antérieures sur les mesures non tarifaires. Pour mettre en évidence l'incidence des prohibitions et des contingents, elle s'appuie sur les notifications à l'OMC et sur divers rapports sur les échanges. Les premières n'offrent qu'un nombre limité d'informations. L'accès à la base de données détaillée sur les restrictions quantitatives est réservé aux membres de l'OMC, et les notifications inverses ne sont généralement pas très circonstanciées. L'étude s'est essentiellement fondée sur les Examens des politiques commerciales de l'OMC. Quatre-vingt-cinq EPC rédigés entre 1998 et 2004 ont été examinés. Ces informations ont été complétées par les données recueillies dans le cadre de l'examen d'autres sources, comme la base de données sur l'accès au marché de la CE, le Report ont the WTO Consistency and Trading Policies by Major Trading Partners publié chaque année par le gouvernement japonais et le National Trade Estimate Report of Foreign Trade Barriers publié tous les ans par le gouvernement américain. Pour la partie concernant les biens d'occasion, quelques rapports spécialisés ont été examinés. Les annexes ci-jointes présentent un choix de données recueillies dans ces sources complémentaires d'information.

6. Les sources susmentionnées apportent certes de nombreux renseignements sur les prohibitions et les contingents, mais présentent des déficiences importantes. Les informations ne sont pas toujours claires et complètes. Elles ne sont pas non plus traitées avec la même profondeur par les différents pays, et certaines sont parfois caduques. Compte tenu des difficultés dérivant de l'insuffisance des données, le Secrétariat a décidé de ne procéder à aucune analyse quantitative. Il est toutefois possible, à partir des renseignements disponibles, de distinguer et d'analyser les profils d'utilisation des prohibitions et contingents dans différents pays, la nature et la gamme des produits concernés, les types de justifications invoquées (économiques et non économiques) et, sur la base de cet examen, de dégager quelques tendances mondiales.

7. Par le passé, les produits agricoles faisaient l'objet d'un traitement distinct des produits industriels dans le cadre du système commercial multilatéral, et ils sont aujourd'hui négociés séparément dans celui du PDD. C'est pour ces raisons, et pour que nos travaux restent gérables, que les produits agricoles et alimentaires ont été en grande partie écartés de la présente étude. Étant donné la forte incidence des prohibitions et contingents appliqués dans ce domaine (les contingents tarifaires en particulier), ces produits mériteraient une analyse séparée, à laquelle il sera éventuellement procédé ultérieurement.

8. Ce rapport examine par ailleurs sommairement d'autres types de restrictions quantitatives, telles que les «restrictions quantitatives appliquées par le biais d'activités de commerce d'État», les «réglementations concernant les mélanges» et les «prix minimum déclenchant une restriction quantitative ». Un bref résumé des conclusions, à la fin de la troisième partie, indique que ces mesures semblent nettement moins souvent utilisées que les prohibitions et contingents. 


\section{Deuxième partie.}

\section{Panorama des disciplines de l'OMC relatives aux restrictions quantitatives}

9. Le GATT établit pour règle fondamentale qu'il est interdit d'appliquer des restrictions quantitatives à l'importation ou à l'exportation de produits en stipulant à l'article XI qu' ' aucune partie contractante n'instituera ou ne maintiendra (...) de prohibitions ou de restrictions autres que des droits de douane, taxes ou autres impositions, que l'application en soit faite au moyen de contingents, de licences d'importation ou d'exportation ou de tout autre procédé ». Il existe néanmoins plusieurs exceptions à cette règle générale. Elles autorisent l'imposition de mesures quantitatives pour des objectifs précis, sous réserve que celles-ci ne soient pas appliquées de façon à constituer soit un moyen de discrimination arbitraire ou injustifiable entre les pays, soit une restriction déguisée au commerce international.

10. Exceptions consenties pour des raisons non économiques :

- l'article XI autorise les prohibitions ou restrictions à l'importation ou à l'exportation, nécessaires pour l'application de normes ou réglementations concernant la classification, le contrôle de la qualité ou la commercialisation de produits destinés au commerce international. $^{2}$

- l'article XX autorise les mesures nécessaires à la réalisation de certains objectifs publics tels que la protection de la moralité publique et la protection de la santé et de la vie des personnes et des animaux ou la préservation des végétaux.

- l'article XXI autorise une dérogation générale aux obligations de l'OMC dans les cas où les intérêts de la sécurité d'un pays sont concernés. Les restrictions quantitatives sont donc admises pour le commerce de produits qui porteraient préjudice aux intérêts de la sécurité d'un pays, les armes et les munitions par exemple.

11. Exceptions consenties pour des raisons économiques :

- Les articles XII et XVIII:B du GATT de 1994 autorisent un pays membre à appliquer des restrictions quantitatives aux importations pour préserver sa position financière extérieure et sa balance des paiements. Pour limiter les risques d'abus, l'Accord précise les conditions permettant d'invoquer ces dispositions. Les mesures restrictives à l'importation ne peuvent être imposées que pour réguler le niveau général des importations et ne pourront pas dépasser ce qui est nécessaire pour remédier à la situation de la balance des paiements. Les pays qui font appel à de telles mesures doivent spécifier les produits concernés et le calendrier pour l'élimination des mesures. Enfin, le GATT établit que, dans toute la mesure du possible, les pays membres devront donner la préférence aux restrictions fondées sur les prix, sauf en période de crise.

- L'article XVIII:C autorise les pays en développement à déroger aux dispositions de l'Accord quand une aide de l'État est nécessaire pour faciliter la création d'une branche de production déterminée. Dans de tels cas, les restrictions quantitatives sont également autorisées. L'imposition de mesures est soumise à notification et à des consultations préalables avec les membres concernés ou/et à l'accord du Conseil général. ${ }^{3}$

\footnotetext{
${ }^{2}$ L'article XIII du GATT de 1994 élargit le principe NPF à l'administration de restrictions quantitatives quand elles sont employées dans le cadre des exceptions à l'article XI. En rège générale, s'agissant de l'application d'interdictions ou de restrictions aux importations et aux exportations, un pays membre doit appliquer le même traitement à tous les autres pays membres.

${ }^{3}$ Dans les cas urgents, la Décision sur les mesures de sauvegarde à des fins de développement du cycle de Tokyo accorde une dérogation aux délais prescrits après consultation avec les pays membres concernés ou accord préalable du Conseil général.
} 
- L'article XIX autorise les mesures nécessaires pour empêcher que l'augmentation brutale des importations ne cause un dommage grave aux producteurs nationaux ou pour soulager ceux qui en ont été victimes.

12. L'OMC autorise aussi les restrictions à l'importation par le biais d'une «levée des obligations » consentie dans des circonstances exceptionnelles par la Conférence ministérielle. L'article XXV:5 du GATT de 1947 autorise une levée partielle des obligations avec le consentement des autres parties contractantes. Quand une telle dérogation est accordée à une partie contractante, celle-ci est autorisée à imposer des restrictions aux importations. Les dérogations consenties au titre de l'Accord de 1947 et toujours en vigueur lorsque l'Accord sur l'OMC est entré en application ont pu être prolongées dans le cadre de ce dernier.

13. Quand des prohibitions et contingents sont effectivement appliqués, le GATT recommande des méthodes pour procéder à leur établissement. Dans toute la mesure du possible, les contingents fixés doivent être «globaux », c'est-à-dire qu'ils représentent le montant total des importations autorisées. Ils peuvent être répartis entre les pays fournisseurs. Dans ce cas, ils doivent l'être en fonction de la part des exportations assurée par ces pays au cours d'une période représentative antérieure. Dans les cas où il est impossible de fixer des contingents, les restrictions peuvent revêtir la forme de licences ou de permis d'importation.

14. S'agissant de l'application des dispositions, les procédures en vigueur pour actualiser les documents de l'OMC sur les mesures non tarifaires se fondent sur deux décisions (G/L/59 et G/L/60) adoptées en décembre 1995 par le Conseil du commerce des marchandises. Ces décisions ont pour objet de relever la transparence de l'application des restrictions quantitatives, notamment par le biais d'un inventaire des mesures non tarifaires mis à la disposition des pays membres pour consultation. Toutes les restrictions quantitatives doivent être notifiées au titre de la décision $\mathrm{G} / \mathrm{L} / 59$, qui en présente une liste en annexe. ${ }^{4}$ Les Membres ont aussi le droit de présenter une notification inverse. En vertu de la décision G/L/60, les mesures non comprises dans la liste complète de la décision G/L/59 peut être notifiées par la partie lésée. ${ }^{5}$

\section{Traitement des restrictions quantitatives dans les accords commerciaux régionaux (ACR)}

15. En général, les $\mathrm{ACR}^{6}$ traitent également des restrictions quantitatives, prohibitions et contingents compris, imposées sur la totalité ou sur une partie des marchandises importées. Il apparait que plusieurs

\footnotetext{
${ }^{4}$ Pour ce qui est des restrictions quantitatives déjà notifiées au titre d'autres Accords de l'OMC, les Membres doivent indiquer qu'une notification antérieure a déjà été présentée et mentionner la référence du document dans lequel elle est reproduite. S'agissant des restrictions quantitatives justifiées au regard des articles XX, XXI ou XVIII, la notification doit donner une description complète du produit, préciser la position du SH et indiquer la justification de la mesure au regard de l'OMC. La Décision dispose que la Division de l'accès aux marchés du Secrétariat doit tenir un répertoire central des restrictions quantitatives. Une notification devrait indiquer la ligne tarifaire visée par la mesure, le type de restriction dont il s'agit, et les motifs pour lesquels la mesure est appliquée et sa justification au regard des instruments de l'OMC. Les effets de la mesure sur le commerce devraient également être exposés.

${ }^{5}$ La notification inverse doit fournir les mêmes renseignements que la notification présentée par un Membre appliquant une restriction quantitative. Si la teneur de la notification inverse fait l'objet de contestations, les observations présentées sont incorporées dans le catalogue des restrictions quantitatives, et d'autres renseignements sont demandés au Membre auteur de la notification. Des consultations peuvent avoir lieu afin de vérifier l'existence et la portée de la mesure.

${ }^{6} \mathrm{~L}$ 'expression «ACR » (accord commercial régional) couvre ici tous les types de zones de libre échange et d'unions douanières.
} 
des principaux ACR mondiaux ont supprimé les restrictions quantitatives sur les échanges entre les parties participantes, suppression qui a pris effet soit immédiatement, soit progressivement.

16. L'OMC a établi un inventaire des dispositions non tarifaires dans les ACR en se fondant sur les informations dégagées de 69 accords notifiés au GATT/OMC (voir le tableau 1). Les analyses des données examinent les dispositions relatives aux restrictions quantitatives de tous ces ACR, mais le rapport de l'OMC ne contient aucune information quant aux types particuliers de mesures employés. L'étude révèle qu'en ce qui concerne les restrictions quantitatives à l'importation, le commerce entre les parties aux accords commerciaux régionaux s'est nettement orienté, ces dernières années, vers une libéralisation plus ample et plus rapide de l'accès aux marchés. Les ACR signés dans les années 90 prévoient beaucoup plus souvent que les ACR antérieurs l'abolition totale des restrictions quantitatives à l'importation de tous les produits (c'est-à-dire aussi bien agricoles qu'industriels). Il a également été relevé que, en comparaison aux zones de libre-échange, les unions douanières tendent à favoriser une libéralisation plus rapide des restrictions quantitatives à l'importation.

Tableau 1. Traitement des restrictions quantitatives à l'importation dans les ACR

\begin{tabular}{|c|c|c|c|c|}
\hline & \multicolumn{2}{|c|}{$\begin{array}{l}\text { Restrictions quantitatives } \\
\text { abolies à la date d'entrée en } \\
\text { vigueur }\end{array}$} & \multirow{2}{*}{$\begin{array}{c}\text { Élimination progressive } \\
\text { des restrictions } \\
\text { quantitatives pour les } \\
\text { produits industriels }\end{array}$} & \multirow{2}{*}{$\begin{array}{c}\text { Les parties conservent } \\
\text { le droit d'imposer de } \\
\text { nouvelles restrictions } \\
\text { quantitatives à } \\
\text { l'importation }^{7}\end{array}$} \\
\hline & $\begin{array}{c}\text { Pour tous les } \\
\text { produits }\end{array}$ & \begin{tabular}{|c|} 
Pour les produits \\
industriels \\
seulement
\end{tabular} & & \\
\hline \begin{tabular}{ll|} 
Accords & commerciaux \\
régionaux & \\
\end{tabular} & 12 & 14 & 23 & 12 \\
\hline Unions douanières & 4 & 1 & 2 & 3 \\
\hline Antérieures à 1990 & 2 & - & 1 & 3 \\
\hline Postérieures à 1990 & 2 & 1 & 1 & - \\
\hline Zones de libre-échange & 8 & 13 & 21 & 9 \\
\hline Antérieures à 1990 & - & - & 4 & 9 \\
\hline Postérieures à 1990 & 8 & 13 & 17 & - \\
\hline
\end{tabular}

Source : Inventaire des dispositions non tarifaires des accords commerciaux régionaux, WT/REG/W/26

\footnotetext{
${ }^{7}$ À moins qu'un accord ne dispose expressément que les parties ne peuvent pas imposer de nouvelles restrictions quantitatives, on suppose qu'elles conservent ce droit.
} 
17. Quelques exemples du traitement des restrictions quantitatives dans les principaux ACR :

- L'ALENA prévoit l'interdiction complète des restrictions quantitatives (pour les nouveaux produits), et les contingents en vigueur au titre des accords régionaux multilatéraux ont été supprimés pour les parties à l'Accord (bien qu'ils existe des clauses de sauvegarde pour le secteur des textiles et de l'habillement qui autorisent de telles restrictions).

- De la même manière, les accords de libre échange que la $\mathrm{CE}$ a conclus avec le Mexique et l'Afrique du Sud, respectivement, suppriment toutes les restrictions quantitatives aux importations et aux exportations bilatérales et interdisent l'instauration de toute nouvelle mesure de cette nature.

- L'Accord de rapprochement économique entre l'Australie et la Nouvelle-Zélande prévoyait l'élimination de la totalité des droits de douane et des restrictions quantitatives sur les marchandises avant le $1^{\text {er }}$ juillet 1990.

- Les pays parties à l'Accord de libre échange de l'ANASE (AFTA) se sont engagés à supprimer toutes les restrictions quantitatives sur les produits couverts par le régime de tarifs préférentiels communs effectifs bien avant l'élimination des autres types de mesures non tarifaires. Des dispositions spéciales s'appliquent aux produits dits «sensibles » et « très sensibles », en vertu desquelles les pays membres les plus développés de l'AFTA ont convenu d'éliminer toutes les restrictions quantitatives avant le $1^{\mathrm{er}}$ janvier 2010 seulement, leurs partenaires moins développés bénéficiant de délais encore plus longs.

- Plusieurs accords de libre échange bilatéraux (Singapour-Australie, Singapour-Japon, Chili-Canada par exemple) n'autorisent pas les restrictions quantitatives, à moins qu'elles ne soient conformes à l'Article XI du GATT.

18. Il arrive toutefois que le recours à certaines restrictions quantitatives reste autorisé pour des produits particuliers, comme les textiles et les automobiles. Ainsi, des contingents tarifaires continuent de limiter le commerce d'automobiles entre les pays membres du MERCOSUR. ${ }^{8}$ De la même manière, par exemple, l'accord de libre échange entre le Chili et la Corée autorise le maintien ou l'instauration de telles restrictions sur l'importation de véhicules d'occasion.

19. Parfois, les ACR autorisent l'application de restrictions quantitatives dans des circonstances dont la définition est si floue qu'elle peut aisément donner lieu à des abus. L'Union douanière d'Afrique australe permet à ses membres d'interdire ou de limiter l'importation ou l'exportation de tout produit pour des «raisons économiques, sociales, culturelles ou toute autre raison dont peut décider le Conseil » des Ministres, qui est son organe directeur suprême (Article 25.1).

20. Enfin, les ACR suivent les règles du commerce multilatéral et y sont conformes en ce que leurs membres se réservent le droit d'agir et de prendre les mesures qu'ils jugent nécessaires pour des objectifs réglementaires non économiques associés à la protection de la santé et de la vie des personnes, des animaux et des végétaux, de la sécurité nationale ou de la moralité publique.

\section{Troisième partie}

\section{Conclusions de l'étude}

21. Les sections qui suivent analysent les pratiques observées en matière de prohibitions et de contingents en s'appuyant sur les informations relatives à ce type de mesures non tarifaires contenues dans

\footnotetext{
${ }^{8}$ Les exportations dépassant le volume fixé sont assujetties à un droit qui devrait diminuer progressivement jusqu'à atteindre 6,9\% à l'horizon 2006. [Automotive Provisions Report, Office of Automotive Affairs, ITA, Département américain du commerce, 17, disponible sur le site: http://www/ita.doc.gov/auto]
} 
les études portant sur les restrictions commerciales. Comme indiqué dans l'introduction, l'évaluation du recours à ces mesures au moyen des données disponibles est limitée pour trois raisons. Primo, les divers rapports commerciaux pertinents traitent de mesures et de pays différents de manière plus ou moins détaillée ; les observations présentées ci-après ne peuvent donc être considérées exhaustives. Secondo, les rapports signalent que dans la plupart des pays, les prohibitions et les contingents évoluent incessamment et rapidement; certains renseignements peuvent donc aisément perdre toute actualité peu après leur publication. Tertio, plusieurs études soulignent qu'il est difficile d'obtenir des informations fiables sur les composantes exactes du régime d'importation appliqué par certains pays. De ce fait, il est probable que les données traduisent des préoccupations concernant l'accès aux grands marchés mondiaux et des politiques plus aisément définissables. Il se peut donc que les restrictions quantitatives appliquées sur les marchés plus étroits et dans les pays en développement soient sous-représentées, de même que les mesures moins transparentes.

\section{Études existantes portant sur l'incidence des restrictions quantitatives}

22. Il existe quelques études fondées sur des inventaires des restrictions quantitatives observées appliquées par certains pays dans différents secteurs ou catégories d'échange. Bon nombre d'entre elles regroupent les mesures non tarifaires ou les restrictions quantitatives dans une même catégorie, ce qui rend difficile d'observer l'utilisation spécifique des prohibitions et des contingents. On trouvera ci-dessous quelques conclusions dégagées des études qui classent les différentes restrictions quantitatives dans des catégories distinctes :

- Une étude de la Banque mondiale réalisée par M. Michalopoulos s'est penchée sur l'évolution des mesures non tarifaires dans les pays en développement entre 1989 et 1998 et conclu que les licences d'importation non automatiques sont de loin la mesure la plus fréquemment appliquée aux produits importés, suivie des prohibitions. ${ }^{9}$

- C. Michalopoulos a également observé que le recours aux prohibitions et contingents, à l'instar d'autres mesures non tarifaires, a diminué dans une vaste majorité de pays au cours de la période examinée.

- Finger et Schuknecht ont examiné dans le détail 33 notifications relatives aux restrictions quantitatives qui on été soumises à l'OMC entre 1996 et 1998. Ils ont observé que les mesures le plus souvent signalées étaient les prohibitions, suivies des licences et des contingents. ${ }^{10}$

\footnotetext{
${ }^{9}$ Constantine Michalopoulos, Trade Policy and Market Access Issues for Developing Countries, Banque mondiale, Washington, 1999. L'analyse prend les ratios de fréquence comme indicateurs de l'existence et du champ d'application des différentes mesures de protection. Les données indiquent par ailleurs que la machinerie et les équipements électriques, les véhicules, les plastiques et les textiles sont les groupes de produits le plus souvent assujettis à des contingents. Au cours de la période examinée, le nombre de pays qui imposent des interdictions sur les textiles, la machinerie et les équipements électriques a diminué, mais il est resté assez stable en ce qui concerne les véhicules.

${ }^{10}$ J. Michael Finger et Ludger Schuknecht, «Market Access Advances and Retreats: the Uruguay Round and Beyond », 1999, disponible sur le site http://econ.worldbank.org/docs/959.pdf. L'étude conclut par ailleurs que les articles XX (Exceptions générales) et XXI (Exceptions concernant la sécurité) sont le plus souvent invoqués pour justifier des restrictions quantitatives. Le paragraphe le plus utilisé de l'article XX est celui qui autorise les restrictions aux fins de protection de la santé et de la vie des personnes et des animaux ou de préservation des végétaux. Les auteurs ont également observé les progrès généraux en matière de réduction des mesures non tarifaires, restrictions quantitatives comprises. Ils ont relevé une diminution notable du recours à de telles mesures, dans les pays en développement comme dans les pays développés.
} 
- D'après une étude engagée par l'USITC en vue de quantifier les mesures non tarifaires et pour laquelle des données provenant de différents rapports commerciaux sont rassemblées, les prohibitions sont la troisième mesure la plus souvent appliquée aux importations, précédées des «licences d'importation» et des «normes, tests, homologation et étiquetage. ${ }^{11}$

23. Le présent rapport a pour ambition d'évaluer la validité des tendances décelées dans les études existantes en ce qui concerne l'utilisation et l'incidence relative des différentes restrictions quantitatives, et d'apporter d'autres informations recueillies auprès de différentes sources de données.

\section{Observations dégagées des notifications à l'OMC}

24. Comme indiqué plus haut, les pays membres de l'OMC sont tenus de notifier les restrictions quantitatives, ainsi qu'une déclaration sur leurs effets commerciaux, et la Division de l'accès aux marchés du Secrétariat de l'Organisation est censée tenir un répertoire central de ces restrictions. L'accès au répertoire est exclusivement réservé aux membres de l'OMC, mais le Secrétariat publie régulièrement un document contenant une liste des membres ayant soumis une notification. La dernière liste disponible a été publiée en mars 2004 et révèle que, depuis 1996, 39 pays ont soumis des notifications de restrictions quantitatives, et 16 ont soumis des notifications de modifications à leurs restrictions quantitatives (voirl'annexe 1). En outre, 33 pays membres ont notifié l'OMC qu'ils n'en appliquent pas. Il semble que dans ces derniers cas, l'obligation de notification ait été généralement interprétée comme ne portant que sur les restrictions quantitatives incompatibles avec l'OMC, tandis que dans d'autres, les pays membres ont peut-être notifié les détails des restrictions quantitatives en vigueur même si elles se justifient au titre des exemptions prévues par les dispositions de l'OMC. Qui plus est, la liste de notifications publiée par l'OMC ne précise pas le type de restrictions signalées par les pays membres.

25. Il est également possible de recueillir des informations sur les prohibitions, les contingents et d'autres formes de restrictions quantitatives dans les notifications portant sur les mesures non tarifaires au Groupe de négociation de l'OMC sur l'accès aux marchés. Les MNT notifiées ne sont pas décrites en grand détail; les informations communiquées portent sur les produits visés, la nature et les effets commerciaux de la mesure en question, et la disposition de l'OMC correspondant à la mesure notifiée. Un examen plus approfondi de ces données aboutit aux observations suivantes :

- La plupart des restrictions quantitatives ont été signalées par les pays développés.

- Quand des produits sont mentionnés, les catégories les plus souvent notifiées sont les textiles, les véhicules et les produits forestiers. Le matériel électrique, les produits sidérurgiques, les produits chimiques, les biens d'occasion, les tapis, les cuirs et les pièces d'automobiles sont également mentionnés à plusieurs reprises.

- S'agissant du type de restrictions quantitatives, les notifications font le plus souvent état d'interdictions d'importation, suivies des contingents et du commerce d'État. Dans plusieurs cas, elles évoquent simplement des restrictions quantitatives, sans préciser le type de mesure appliquée (prohibition, contingent ou licence).

\footnotetext{
${ }^{11}$ L'Office of Economics de l'International Trade Commission américaine conduit actuellement des études dans le but d'améliorer la quantification des effets des mesures non tarifaires (MNT) sur les flux d'échanges et d'autres variables économiques. L'élément central de ces travaux est l'élaboration d'une base de données des MNT contenant des renseignements sur 53 pays. Elle fournit également des informations sur les produits (biens et services) et les secteurs visés par ces mesures, ainsi que des sources de référence. Un panorama de cette étude et de quelques observations préliminaires a été présenté à l'Atelier de l'APEC sur le renforcement des capacités consacré aux méthodes quantitatives d'évaluation des mesures non tarifaires et à la facilitation commerciale qui s'est tenu du 8 au 10 octobre 2003 à Bangkok (Thaïlande).
} 
TD/TC/WP(2004)28/FINAL

Tableau 2. Notifications de restrictions quantitatives soumises au Groupe de négociations de l'OMC sur l'accès aux marchés en vertu des instructions du PDD

\begin{tabular}{|l|l|}
\hline Nature de la mesure & Incidence \\
\hline Restriction quantitative non spécifiée & 9 \\
\hline Interdictions & 17 \\
\hline Contingents & 9 \\
\hline «Interdictions ou contingents »* & 15 \\
\hline Commerce d'État & 5 \\
\hline Total & 55 \\
\hline
\end{tabular}

26. En mai 2004, les pays qui avaient soumis des notifications étaient les suivants : Argentine, Bangladesh, Chine, Égypte, Japon, Corée, Mexique, Malaisie, Nouvelle-Zélande, Norvège, Philippines, Suisse, Taiwan, et Uruguay. Le chiffre correspondant aux interdictions prend en compte le nombre inhabituellement élevé de mesures notifiées par un membre.

* Un pays a utilisé l’expression « Interdictions ou contingents » pour décrire les mesures notifiées.

Source : OCDE, établi à partir des notifications de mesures non tarifaires soumises au Groupe de négociations de l'OMC sur l'accès aux marchés (TN/MA/A*)

27. Étant donné que seuls quelques 39 membres de l'OMC ont soumis des notifications relatives aux restrictions quantitatives (à l'exportation et/ou l'importation) et que les informations communiquées ne sont guère détaillées, les sources de l'OMC ne fournissent pas de renseignements suffisants sur les différents types de restrictions appliqués par ses pays membres. Ces données indiquent qu'en pratique, l'obligation de notification de l'OMC n'atteint pas entièrement son objectif d'accroître la transparence dans ce domaine.

Questions relatives aux restrictions quantitatives dans le cadre du processus de règlement des différends de l'OMC

28. Depuis 1995, un nombre substantiel de demandes de consultations associées aux restrictions à l'importation ont été soumises à l'organe de règlement des différends de l'OMC. La grande majorité de ces demandes ont cependant trait aux produits agricoles, et seuls quelques conflits portent sur les produits non agricoles. Le tableau 3 présente les cas relativement peu nombreux ayant trait aux prohibitions et contingents. 
Tableau 3. Synthèse des plaintes à l'OMC

\begin{tabular}{|c|c|c|}
\hline Mesure & Partie plaignante & Problème \\
\hline $\begin{array}{l}\text { Mesures concernant l'amiante et } \\
\text { les produits contenant de } \\
\text { l'amiante }(\mathrm{CE})\end{array}$ & Canada & $\begin{array}{l}\text { Les mesures prises par la France } \\
\text { pour interdire l'importation } \\
\text { d'amiante et de produits } \\
\text { contenant de l'amiante afin de } \\
\text { protéger la santé et la sécurité } \\
\text { humaine. }\end{array}$ \\
\hline $\begin{array}{l}\text { Interdiction d'importation de } \\
\text { polyéthylène et de polypropylène } \\
\text { (Malaisie) }\end{array}$ & Singapour & $\begin{array}{l}\text { L'imposition d'interdictions à } \\
\text { l'importation de polyéthylène et } \\
\text { de polypropylène afin protéger la } \\
\text { santé et la sécurité humaine. }\end{array}$ \\
\hline $\begin{array}{l}\text { Restrictions quantitatives sur les } \\
\text { importations de produits } \\
\text { agricoles, textiles et industriels } \\
\text { (Inde) }\end{array}$ & $\begin{array}{l}\text { Australie, Canada, CE, Nouvelle- } \\
\text { Zélande, Suisse, États-Unis }\end{array}$ & $\begin{array}{l}\text { Les restrictions quantitatives (y } \\
\text { compris des interdictions } \\
\text { d'importation) maintenues sur } \\
\text { plus de } 2700 \text { lignes tarifaires de } \\
\text { produits agricoles et industriels } \\
\text { pour des raisons de balance des } \\
\text { paiements. }\end{array}$ \\
\hline 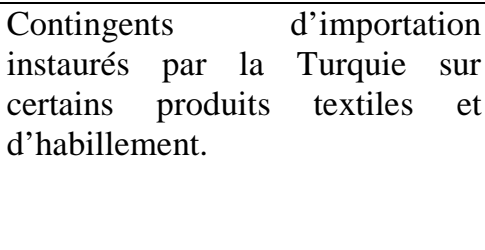 & $\begin{array}{l}\text { Hong Kong, Chine, Inde, } \\
\text { Thaillande }\end{array}$ & $\begin{array}{l}\text { Les contingents sur les produits } \\
\text { textiles et d'habillement instaurés } \\
\text { par la Turquie dans le cadre de la } \\
\text { mise en œuvre de l'union } \\
\text { douanière entre ce pays et la } \\
\text { Communauté européenne. }\end{array}$ \\
\hline
\end{tabular}

Source : OCDE, établi à partir des documents WT/DS135/AB/R, WT/DS1/1, WT/DS91/3, WT/DS29/2 de l'OMC.

\section{Le recours aux prohibitions et contingents pour des raisons économiques}

29. Le recours aux prohibitions et contingents pour des raisons économiques a sensiblement fléchi ces dernières années. Les États invoquent bien plus souvent les questions de santé, de sécurité, d'environnement et d'autres problèmes pour appliquer ce type de restrictions. La majorité des pays qui appliquaient des mesures de cette nature pour des motifs économiques dans les années 90 y ont par la suite renoncé, ou ont substantiellement limité leur utilisation. Ils ont dans l'ensemble remplacé les interdictions par des licences d'importation, lesquelles peuvent être automatiques ou non automatiques. Quelques exceptions demeurent toutefois, qui sont décrites dans les sections qui suivent.

\section{Restrictions appliquées à des fins de balance des paiements ${ }^{12}$}

30. Les archives du Comité des restrictions appliquées à des fins de balance des paiements de l'OMC et les examens des politiques commerciales indiquent que l'application de restrictions quantitatives à des fins de balance des paiements a considérablement diminué au cours de la décennie écoulée. Cette évolution tient en grande partie au resserrement des règles en vigueur du GATT à la suite du cycle de l'Uruguay et de la surveillance plus rigoureuse associée à l'utilisation de ces mesures.

${ }^{12}$ Ce document traite uniquement des mesures faisant intervenir des restrictions quantitatives appliquées pour des raisons de balance des paiements, bien que plusieurs autres mesures existent également (surtaxes à l'importation, etc.). 
31. Le Mémorandum d'accord sur les dispositions relatives à la balance des paiements du cycle d'Uruguay a apporté plusieurs clarifications aux articles XII et XVIII du GATT de 1947 et de 1994, qui traitent de la balance des paiements : les mesures fondées sur les prix, à savoir les surtaxes à l'importation, sont préférées aux restrictions quantitatives; ces dernières ne sont autorisées que dans des circonstances exceptionnelles, et les mesures adoptées pour des raisons de balance des paiements ne peuvent l'être que pour réguler le niveau global des importations (autrement dit, elles doivent s'appliquer à toutes les importations et ne doivent pas protéger des secteurs particuliers de la concurrence). Par ailleurs, le Mémorandum établit des délais de notification rigoureux et des obligations explicites en matière de documentation, et autorise les Membres concernés par les mesures instituées, mais non notifiées, par d'autres Membres à soumettre une «notification inverse ».

32. Conformément aux termes du GATT de 1947 et de 1994, tout Membre qui impose des restrictions à des fins de balance des paiements est tenu de consulter le Comité de la balance des paiements afin de déterminer si l'application de mesures restrictives est nécessaire ou souhaitable pour résoudre ses problèmes. Conformément aux dispositions relatives à la balance des paiements, le Comité travaille en étroite collaboration avec le Fonds monétaire international dans la conduite de ces consultations. ${ }^{13}$

33. Ces clarifications se sont avérées très utiles pour assurer que les dispositions relatives à la balance des paiements soient utilisées aux fins visées à l'origine, à savoir pour permettre aux pays confrontés à une crise de la balance des paiements d'imposer des mesures temporaires jusqu'à ce que la situation s'améliore. Auparavant, les pays appliquaient souvent des restrictions quantitatives ou des interdictions de manière sélective à des secteurs particuliers et les maintenaient sur de longues périodes. À l'heure actuelle, ils sont moins nombreux à faire appel aux restrictions quantitatives pour sauvegarder l'équilibre de leur balance des paiements et les maintiennent moins longtemps en vigueur.

34. L'examen des EPC et des rapports annuels du Comité des restrictions appliquées à des fins de balance des paiements révèle que ces dernières années, très peu de pays ont appliqué des mesures de restriction à l'importation et que la majeure partie d'entre eux les ont maintenant abolies. En général, les pays optent soit pour les surtaxes à l'importation, soit pour des restrictions quantitatives. ${ }^{14}$ Depuis 1995, huit pays seulement (Burundi, Nigeria, Bangladesh, Inde, Pakistan, Égypte, Philippines et Tunisie) ont notifié à l'OMC le recours à des interdictions d'importation à des fins de balance des paiements. La majorité d'entre eux ont appliqué ces mesures restrictives à quelques produits seulement, le plus souvent aux produits agricoles, aux textiles et aux vêtements et, dans une moindre mesure, aux automobiles. ${ }^{15}$

\footnotetext{
${ }^{13}$ Le FMI fournit des documents, généralement un rapport sur les évolutions économiques récentes, comprenant des statistiques relatives à la balance des paiements, et présente une déclaration formelle au Comité. Dans le cadre de consultations simplifiées, il fournit des documents, mais ne s'adresse pas au Comité.

${ }^{14}$ Plusieurs pays ont appliqué des surtaxes à l'importation pour des raisons de balance des paiements dans les années 90. Il s'agissait essentiellement des pays en transition (Pologne, Hongrie, République slovaque, République tchèque, Bulgarie et Roumanie), ainsi que le Sri Lanka et l'Afrique du Sud. Ces mesures ont été abandonnées dans la seconde moitié des années 90, la Roumanie et la République slovaque ayant été les dernières à lever ces restrictions en 2001.

${ }^{15}$ Exemples de mesures invoquées et abolies pour des raisons de balance des paiements : Israël a renoncé aux dispositions relatives à la balance des paiements en 1995. Le pays avait appliqué des restrictions à l'importation en vertu de ces dispositions plusieurs fois depuis 1961. Les plus récentes s'appliquaient aux produits agricoles, et ont été transformées en droits de douane et en contingents tarifaires. Les Philippines ont eu recours à des restrictions sur le charbon, les produits du charbon et les produits agricoles, mesures qui ont été supprimées en 1999. Le Nigeria, en 1999, et la Tunisie, en 2001, ont levé toutes les interdictions d'importation sur les automobiles. Entre 1993 et 2000 , le Burundi avait progressivement allongé la liste d'importations interdites ou contrôlées, les autorités invoquant un déficit en devises pour justifier ces mesures. Après 2000, face aux avancées du processus de paix, les interdictions ont été progressivement levées. Enfin, le Pakistan interdit l'importation de plusieurs produits pour des raisons de balance des paiements depuis 1997, bien que le nombre de produits concernés ait été graduellement restreint. Les principales
} 
35. Actuellement, le Bangladesh est le seul Membre de l'OMC à appliquer des mesures notifiées relatives à la balance des paiements. Le pays fait depuis longtemps appel à des restrictions à l'importation pour des raisons de balance des paiements. En 2000, quelque 2,2\% des lignes tarifaires à quatre chiffres du SH étaient assujetties à des interdictions ou restrictions touchant au commerce, ${ }^{16}$ mais les listes d'importations interdites et limitées ont depuis lors été réduites. Les restrictions qui touchent au commerce s'appliquaient ou continuent de s'appliquer essentiellement à certains produits agricoles, matériaux d'emballage et produits de l'industrie textile, les interdictions d'importation concernant pour leur part les tissus, et les importations de tissu écru sont limitées à l'industrie de la confection.

36. L'Inde offre un cas intéressant de recours aux restrictions quantitatives pour des raisons de balance des paiements. Depuis les années 50, dans le cadre de sa politique commerciale, le pays avait recours à ces mesures pour des motifs économiques. En 1991, il a engagé une réforme commerciale, mais maintenu les restrictions sur les importations de 1429 articles en invoquant des problèmes de balance des paiements. À partir de 1995, dans le cadre du Comité de la balance des paiements puis, en 1997, d'une procédure de règlement des différends, les Membres de l'OMC ont contesté la nécessité pour l'Inde de maintenir ces mesures. En 1999, une décision de l'OMC rendue en réponse à une plainte déposée par les États-Unis a enjoint l'Inde à mettre un terme aux restrictions sur tous les produits avant le $1^{\text {er }}$ avril 2001, au motif que la position de sa balance des paiements s'était redressée. ${ }^{17}$ Les restrictions appliquées aux 714 derniers articles ont été levées dans les délais imposés. Sur les 715 produits couverts par la dernière vague de libéralisation, 342 étaient des produits textiles, 147 des produits agricoles, et les 226 restants des produits manufacturés, les automobiles notamment.

\section{Protection industrielle}

37. Tout comme les mesures visant à sauvegarder l'équilibre de la balance des paiements, les restrictions à l'importation (prohibitions et contingents) pour des raisons de protection industrielle sont rares, ${ }^{18}$ à l'exception notable des textiles et des vêtements, analysée plus loin. L'article XVIII:C du GATT, qui autorise les restrictions quantitatives à ces fins, n'a été invoqué qu'en trois occasions depuis l'entrée en vigueur de l'Accord instituant l'OMC. ${ }^{19}$

38. Comme l'indiquent les EPC, un nombre restreint d'autres pays utilisent les prohibitions et contingents dans le but déclaré de protéger l'industrie locale. Dans la plupart des cas, néanmoins, le recours à ces mesures diminue. Les États y renoncent souvent en faveur de licences d'importation non automatiques et d'autres types de mesures généralement moins préjudiciables au commerce.

interdictions appliquées pour des motifs commerciaux à de nombreux produits textiles et articles d'habillement ainsi qu'aux châssis de camions ont été progressivement supprimées entre juillet 2000 et janvier 2001.

${ }^{16}$ Rapport sur l'EPC du Bangladesh (2000).

${ }^{17}$ Inde - Restrictions quantitatives à l'importation de produits agricoles, textiles et industriels - Rapport du groupe spécial, WT/DS90/R, avril 1999.

${ }^{18}$ Il n'existe pas d'organe désigné auquel des notifications de cette nature devraient être adressées. Le Conseil du commerce des marchandises, qui « agit sous la supervision globale du Conseil général », est chargé de « surveille(r) le fonctionnement des accords commerciaux multilatéraux mentionnés à l'annexe $1 \mathrm{~A} »$. Ceux-ci comprennent le GATT de 1994, dont l'article XVIII:C fait partie. Le Comité du commerce et du développement, pour sa part, a compétence, selon les termes de son mandat, pour «examiner toute question susceptible de surgir quant à l'application ou l'utilisation des dispositions spéciales des accords commerciaux multilatéraux et des décisions ministérielles connexes en faveur des pays Membres en développement et rendre compte au Conseil général pour qu'il se prononce ».

${ }_{19}$ Malaisie - polypropylène et polyéthylène (1995);.Colombie - importations de sel (1998), et Bangladesh - poussins, œufs, cartons et sel (2002). Source : OMC. 
39. À titre d'exemple, la Papouasie Nouvelle-Guinée est un PMA qui faisait appel à des interdictions pour protéger les producteurs locaux de la concurrence étrangère. Les autorités ont de fait accordé à ceux-ci un statut de monopole en établissant à l'origine des prohibitions et des contingents d'importation, mais elles ont récemment remplacé ces restrictions par des droits de douane élevés voire, souvent, prohibitifs. On citera parmi les secteurs ainsi protégés par le passé l'industrie du ciment et certaines industries alimentaires (sucre, poisson et bœuf).

40. Le Nigeria interdit toujours l'importation de nombreux produits, essentiellement des produits agricoles, mais aussi de textiles, de bicyclettes, de pâte dentifrice, de crayons et de stylos billes, etc. Les autorités soutiennent que ces mesures sont motivées par des raisons économiques. Leur compatibilité avec les règles de l'OMC n'est pas claire. ${ }^{20}$

41. Les EPC indiquent par ailleurs que l'Indonésie et la Malaisie utilisent plusieurs sortes de restrictions quantitatives (contingents, prohibitions et licences d'importation) pour protéger certains secteurs de l'industrie nationale, mais ces régimes évoluent rapidement et les conclusions des différents rapports commerciaux sont souvent contradictoires. Il est souvent difficile de savoir quels produits sont assujettis à de telles restrictions et quelle forme exacte celles-ci revêtent. L'Indonésie a maintenu un interdiction d'importation et des restrictions quantitatives sur divers produits afin de protéger les industries nationales, par exemple une interdiction type d'importation sur les automobiles et les motocyclettes et des contingents d'importation sur les véhicules commerciaux. Par suite de la déréglementation récente, le nombre de produits concernés diminue chaque année. Les autorités ont indiqué au Secrétariat qu'en décembre 2002, l'importation de 170 produits à neuf chiffres du SH était limitée, et celle de 41 autres était interdite. La Malaisie fait aussi appel à la fois à des licences d'importation et à des contingents sur une base discrétionnaire pour réguler les flux d'importation en vue de développer certaines industries embryonnaires ou stratégiques et d'intensifier les liens en aval et en amont. ${ }^{21}$ Ainsi, des contingents d'importation et des mécanismes de licence sont appliqués aux pièces d'automobile importées.

42. Le recours aux prohibitions et contingents est également observé dans le secteur automobile. D'après les EPC, le Venezuela et le Brésil ont ainsi tous deux fait appel à des restrictions quantitatives pour protéger leurs industries nationales. Le Venezuela interdit l'importation d'automobiles équipées de châssis et de moteurs usagés (véhicules de transport public ou taxis exceptés) dans l'intention déclarée de jeter les bases réglementaires nécessaires au fonctionnement et au développement d'une industrie automobile nationale. Le Brésil a supprimé ses contingents d'importation sur les produits automobiles en 1999, quand le régime automobile en vigueur a pris fin. On trouvera au tableau 4 ci-dessous d'autres exemples de pays qui appliquent des prohibitions et contingents aux importations de véhicules et de pièces automobiles.

\footnotetext{
${ }^{20}$ Base de données MAD de l'UE.

${ }^{21}$ Document de la CEAP et de l'OMC G/LIC/N/3/MYS/1, 19 décembre 1997.
} 
TD/TC/WP(2004)28/FINAL

Tableau 4. Prohibitions et contingents appliqués aux importations de nouveaux véhicules automobiles

\begin{tabular}{|c|c|}
\hline Argentine & $\begin{array}{l}\text { Les véhicules étrangers sans équivalent national sont assujettis à des contingents } \\
\text { d'importation. Ce système limite les importations à un pourcentage de la production } \\
\text { totale nationale. }\end{array}$ \\
\hline Brésil & L'importation des automobiles particulières fonctionnant au diesel est interdite. \\
\hline Chine & $\begin{array}{l}\text { Les contingents appliqués aux automobiles seront progressivement supprimés d'ici à } \\
2005 \text {, avec un montant initial de } 6 \text { milliards de dollars, montant supérieur au niveau } \\
\text { réel des échanges avant la mise en œuvre de la politique industrielle automobile de } \\
\text { 1994. Les contingents augmenteront de } 15 \% \text { par an jusqu'à leur suppression. }\end{array}$ \\
\hline Taipei (Chine) & $\begin{array}{l}\text { L'importation de véhicules diesel (à l'exception des Jeeps) et des automobiles } \\
\text { équipées de moteurs à deux temps est interdite. }\end{array}$ \\
\hline Colombie & L'importation de véhicules neufs des années précédentes est interdite. \\
\hline Équateur & L’importation de véhicules neufs des années précédentes est interdite. \\
\hline Malaisie & L’importation des véhicules automobiles d'Israël est interdite. \\
\hline Mexique & $\begin{array}{l}\text { Les véhicules qui entrent dans le cadre de l'accord de libre échange entre le Mexique } \\
\text { et l'UE sont assujettis à des contingents jusqu'à } 2007 \text {. Les importations au-delà de ce } \\
\text { contingent (15\% du marché total de l'année précédente pour des véhicules similaires) } \\
\text { sont assujetties à un droit de } 10 \% \text {. L'entrée de jusqu'à } 50000 \text { nouveaux véhicules } \\
\text { fabriqués au Brésil est autorisée chaque année au taux tarifaire de } 8 \% \text {, les véhicules } \\
\text { supplémentaires étant soumis à un droit de } 20 \% \text {. }\end{array}$ \\
\hline Singapour & $\begin{array}{l}\text { Le mécanisme de contingentement des véhicules prédétermine le nombre } \\
\text { d'automobiles qui sera immatriculé au cours de l'année. Ce nombre est calculé d'après } \\
\text { celui de l'année précédente, augmenté de } 3 \% \text { et ajouté au nombre d'automobiles qui } \\
\text { devraient être mises au rebut. }\end{array}$ \\
\hline Thaïlande & L'importation d'autobus de plus de 30 places est interdite. \\
\hline Venezuela & nouveaux véhicules des années précédentes est interdite. \\
\hline
\end{tabular}

Source : Département américain du commerce, International Trade Administration, Office of Automotive Affairs, Compilation of Foreign Motor Vehicle Import Requirements, décembre 2003.

43. En parallèle, les pays plus développés ont aussi fait appel aux restrictions quantitatives aux fins de protection industrielle. A une certaine époque, la République de Corée a mis en place un dispositif de restrictions aux importations pour des motifs économiques industriels, dispositif qui n'a été abandonné qu'à la fin des années 90. Celui-ci, connu sous le nom de «mécanisme de diversification des importations », avait été établi en 1978 dans l'objectif de remédier au déséquilibre commercial excessif avec le Japon et de favoriser une structure d'importation équilibrée sur le plan géographique. Conformément à ses engagements envers l'OMC et à l'ensemble de mesures de stabilisation du FMI, la Corée a avancé la levée des interdictions d'importation du 31 décembre 1999 au 30 juin 1999. Le mécanisme a été supprimé en trois phases. Les derniers articles à 10 chiffres du SH (tous retirés de la liste de produits sur lesquels portait le mécanisme à la fin de juin 1999) couvraient certains types d'automobiles (dont les jeeps), les pneus radiaux pour automobiles, les pièces automobiles, les excavatrices, les centres 
d'usinage, les téléviseurs en couleur (de plus de 25 pouces), les magnétoscopes, les appareils radiotéléphoniques portables, les cuiseurs de riz électrique et les appareils photos (pellicules de $35 \mathrm{~mm}$ ). ${ }^{22}$

44. Beaucoup de pays ont remplacé leurs prohibitions et contingents par des procédures de licences non automatiques. Les données contenues dans les EPC indiquent cependant que plusieurs de ces licences d'importation sont de fait des interdictions puisqu'il est jugé impossible de recevoir une réponse affirmative à une demande de licence. Ainsi, l'EPC de la Thailande signale qu'il est pratiquement impossible de recevoir des licences pour l'importation de certains véhicules et pour les pierres monumentales et les pierres de construction ouvrées.

45. En vertu de son accord d'accession à l'OMC, la Chine a été contrainte de réduire les contingents et prohibitions d'importation auxquels elle avait coutume de faire appel pour limiter les échanges. Elle a donc progressivement levé bon nombre de ces mesures, sur plusieurs années. Quelques rapports commerciaux indiquent néanmoins que pour certains produits, comme les automobiles, la mise en œuvre du dispositif de contingentement requis a été marquée par des retards, un manque de transparence et des allocations inappropriées en 2002 comme en 2003.

\section{Le cas des textiles et des vêtements}

46. Les textiles et les vêtements sont le seul groupe de produits (produits agricoles exceptés) qui ont souvent fait l'objet de restrictions quantitatives, sous forme de contingents d'importation, à des fins de protection industrielle. La plupart de ces restrictions seront toutefois abolies à l'horizon 2005, date à laquelle l'Accord sur les textiles et les vêtements (ATV) entrera pleinement en vigueur.

47. Pendant plusieurs décennies, le commerce international des textiles a été assujetti à un mécanisme complexe de restrictions quantitatives bilatérales que certains pays développés ont instauré et maintenu afin de protéger leurs propres industries textiles et de la confection de la concurrence croissante des producteurs des pays en développement. Ces contingents s'inscrivent dans le cadre de l'Arrangement multifibres (AMF). Si certaines nations entretenant des liens politiques solides avec les pays développés ont bénéficié d'accords préférentiels qui augmentaient leurs contingents ou les éliminaient, bon nombre de pays en développement ont pâti d'un accès au marché rigoureusement limité. Conclu en 1995, l'ATV, issu des négociations du cycle de l'Uruguay, assujettit le commerce des textiles et des vêtements aux principes fondamentaux de l'OMC de non-discrimination et de traitement national. L'accord stipule que les Membres de l'OMC doivent l'appliquer pendant 10 ans, du $1^{\text {er }}$ janvier 1995 au $1^{\text {er }}$ janvier 2005. À compter de cette dernière date, les contingents sur les textiles et les vêtements ne seront utilisés qu'à des fins de balance des paiements (c'est par exemple le cas du Bangladesh), mais pas de protection industrielle.

48. Il existe un nombre considérable d'analyses des effets économiques et commerciaux des contingents sur les produits textiles et les vêtements. Un rapport antérieur de la Direction des échanges de l'OCDE (TD/TC/WP(2003)2/REV1) présente un examen des études quantitatives portant sur la libéralisation des marchés dans ce secteur. ${ }^{23}$ Le rapport conclut que toutes les études examinées prévoient une amélioration du bien-être mondial par suite des réformes engagées au titre de l'ATV, mais les conclusions diffèrent quant à la répartition de ses retombées favorables. Certains analystes voient dans les

\footnotetext{
${ }^{22}$ À la mi-1999, la part de marché de plusieurs produits japonais en vogue sur lesquels les interdictions au titre du mécanisme de diversification des importations avaient été levées à la fin de 1998 avait atteint jusqu'à $92 \%$. Il s'agissait notamment des fraiseuses à commande numérique, des caméscopes, des produits de céramique et de porcelaine et des montres analogiques (Digital Chosunllbo [en ligne], 3 juin 1999. Document disponible sur le site: http://www.chosun.com/w21data/html/news/199906/ 199906030454.html

${ }^{23}$ Libéralisation du commerce dans les secteurs textiles et de l'habillement: Examen des études quantitatives, OCDE, Paris, 2003.
} 
pays en développement les principaux bénéficiaires de ces réformes, d'autres faisant observer pour leur part que les effets varieront vraisemblablement d'un pays à l'autre. Les pays développés (Canada, Union européenne et États-Unis) devraient en tirer des avantages substantiels compte tenu de la baisse des prix à la consommation et de l'allocation plus efficace des ressources.

\section{Prohibitions d'importation pour des motifs non économiques}

49. Le nombre de produits que les pays soumettent en général à des interdictions pour des raisons autres qu'économiques - par exemple pour des motifs de santé (hygiène et assainissement), de sûreté, d'environnement (protection des espèces animales et végétales), de moralité, de culture, de religion et de sécurité - est considérable. Il ressort de notre étude qu'il a légèrement augmenté ces dernières années. Il est néanmoins impossible de quantifier cette évolution. Dans de nombreux pays, l'interdiction d'importation pour des motifs non économiques s'applique aux produits suivants :

- Marchandises de contrefaçon et matériel de production associé (pièces de monnaie et billets compris).

- Articles contrevenant aux brevets et autres droits de propriété intellectuelle.

- Narcotiques.

- Articles interdits pour des raisons de sécurité (armes, munitions, explosifs par exemple).

- Produits contenant des substances interdites à des fins de protection de l'environnement et/ou de santé et de sécurité publiques.

- Documents susceptibles de heurter la moralité publique, la culture ou la religion.

- Certaines espèces animales et végétales protégées.

- Certains produits usagés.

50. Les trois premières catégories (marchandises de contrefaçon, articles contrevenant aux DPI et narcotiques) sont inscrits sur la liste des produits interdits de quasiment tous les pays (85) examinés par l'OMC entre 1998 et 2004. Les armes, munitions et explosifs figurent dans bien des cas parmi les produits interdits, et dans d'autres sont assujettis à des licences d'importation ou ne peuvent être importés que par des entreprises publiques.

51. Les interdictions ont en majorité été instaurées pour des motifs de protection de l'environnement et de santé et sécurité publiques, ou les deux à la fois. Ces produits entrent généralement dans deux catégories. D'abord, les pays interdisent le plus souvent les produits qui contiennent des substances qu'ils jugent dangereuses pour l'environnement et pour la santé humaine et animale. L'incidence de ces interdictions semble augmenter, surtout dans les pays développés qui appliquent des réglementations plus rigoureuses en matière d'environnement, de santé et de sécurité que le pays en développement. Différents pays imposent souvent des licences ou des interdictions d'importation aux mêmes types de substances ou de produits. Les rapports commerciaux signalent que les interdictions ayant la plus haute incidence portent sur différentes sortes d'amiante et sur les déchets humains, animaux et industriels. ${ }^{24}$

52. Les bases de données sur l'environnement de l'OMC, publiées chaque année de 1997 à 2001, offrent d'autres sources possibles d'informations sur les restrictions quantitatives introduites pour des raisons liées à l'environnement. Ces documents rassemblent toutes les notifications à l'OMC dans ce domaine, groupées en fonction des accords au titre desquels elles ont été publiées. Il en ressort que le nombre de mesures d'ordre environnemental notifiées en vertu de l'Accord sur les restrictions quantitatives

\footnotetext{
${ }^{24}$ Pour de plus amples détails, se reporter à l'annexe 3 qui contient la liste des produits assujettis à des interdictions par différents pays établie à partir des EPC.
} 
est bien inférieur à celui des mesures adoptées au titre d'autres accords, comme l'Accord sur les obstacles techniques au commerce, l'Accord sur l'application des mesures sanitaires et phytosanitaires, l'Accord SMC ou l'Accord sur l'agriculture. ${ }^{25}$ Seules les éditions de 2000 et 2001 de la base de données contenaient assez d'informations permettant de déterminer le type exact des mesures restrictives concernées. Il a par ailleurs été observé que les mesures notifiées en vertu de l'Accord sur les obstacles techniques au commerce mentionnent également des prohibitions et contingents dans quelques cas. L'annexe 2 présente les prohibitions et contingents associés à l'environnement signalés en 2000 et 2003.

53. La deuxième catégorie par ordre d'importance est constituée de biens usagés que certains pays jugent préjudiciables à l'environnement, de même qu'à la santé et à la sécurité humaines. Ce sont essentiellement les pays en développement qui les interdisent; autrement, ce commerce pourrait représenter un marché d'exportation considérable pour les pays développés. Les politiques commerciales appliquées à cette catégorie soulèvent de nombreuses questions. Dans ce domaine, le commerce international est souvent limité par des restrictions quantitatives et d'autres mesures commerciales, et les justifications données par les autorités quand elles interdisent ce commerce ou y interviennent d'une façon ou d'une autre sont variées et souvent vagues. Les restrictions quantitatives qui pèsent sur les marchandises d'occasion seront examinées séparément à la section suivante.

54. Il ressort des rapports des EPC que plusieurs pays développés ont établi un système complexe qui réglemente l'importation de substances dangereuses par le biais d'interdictions ou de licences obligatoires. L'Union européenne a ainsi mis un en œuvre un dispositif qui vise à protéger le public en réglementant la localisation et l'utilisation des substances dangereuses sur le marché communautaire, y compris dans le cadre des importations. La liste des substances concernées est régulièrement actualisée de manière à tenir compte des avancées techniques. ${ }^{26}$ L'Union européenne applique par ailleurs la procédure de consentement préalable en connaissance de cause (procédure PIC) établie par le Programme des Nations Unies pour l'environnement et l'Organisation des Nations Unies pour l'alimentation et l'agriculture (FAO).

55. Les interdictions pour des raisons liées à l'environnement et à la santé et à la sécurité humaines sont appliquées unilatéralement et aussi, souvent, dans le cadre d'accords multilatéraux ou de conventions. Les accords multilatéraux le plus souvent invoqués comme justification aux interdictions d'importation sont les suivants :

- Convention sur le commerce international des espèces de faune et de flore sauvages menacées d'extinction

- Convention de Bâle sur le contrôle des mouvements transfrontières de déchets dangereux et de leur élimination

- Convention de Stockholm sur les polluants organiques persistants

- Convention de Rotterdam sur la procédure de consentement préalable en connaissance de cause applicable à certains produits chimiques et pesticides dangereux qui font l'objet d'un commerce international

- Protocole de Montréal relatif à des substances qui appauvrissent la couche d'ozone.

\footnotetext{
${ }^{25}$ Nombre de mesures associées à l'environnement notifiées entre 1997 et 2001 : Accord sur les obstacles techniques au commerce : 435 ; Accord sur l'application des mesures sanitaires et phytosanitaires : 95 ; Accord SMC : 133 ; Accord sur l'agriculture: 150; Accord sur les procédures de licences d'importation: 79 ; restrictions quantitatives : 12. WT/CTE/EDB/1 Annexe 3, p 73.

${ }^{26}$ Directive 76/769/CEE du Conseil, telle que modifiée.
} 


\section{Encadré 1. Compatibilité des AEM et de l'OMC}

La relation entre les accords de l'OMC et les mesures commerciales en vigueur au titre des accords environnementaux multilatéraux (AEM) présente un problème qui fait actuellement l'objet de discussions au sein de l'OMC. Selon cette dernière, seuls 20 des plus de 200 AEM en vigueur comportent des dispositions relatives au commerce. Certaines de ces mesures sont des restrictions quantitatives à l'importation.

Comme l'indique l'OMC, « les Membres de l'OMC sont principalement convenus de clarifier la relation juridique existant entre les règles de l'OMC et les $\mathrm{AEM}$, plutôt que de laisser à l'Organe de règlement des différends de l'OMC la charge de résoudre cette question ponctuellement (au cas où un différend formel lui serait soumis). Cependant, ils ont explicitement déclaré que ces négociations devraient se limiter à l'applicabilité des règles de l'OMC aux Membres de l'OMC qui sont parties à un AEM. En d'autres termes, il ne s'agit pas d'aborder l'applicabilité de ces règles aux différends entre un pays partie à un AEM et un autre pays qui ne l'est pas. Cette restriction s'explique par le fait que les Membres de l'OMC étaient prêts à ce que des négociations définissent la relation entre les règles de l'OMC et des AEM auxquels ils sont parties, mais n'étaient pas disposés à ce que des négociations modifient leurs droits et obligations au titre de l'OMC à l'égard d'AEM dont ils n'étaient pas parties. De plus, les négociations à mener au titre du paragraphe 31 i) et ii) sont minutieusement délimitées au paragraphe 32 de la Déclaration de Doha : «Les négociations menées au titre du paragraphe 31 i) et ii) seront compatibles avec le caractère ouvert et non discriminatoire du système commercial multilatéral, n'accroîtront pas ou ne diminueront pas les droits et obligations des Membres au titre des accords de l'OMC existants, en particulier l'Accord sur l'application des mesures sanitaires et phytosanitaires, et ne modifieront pas non plus l'équilibre entre ces droits et obligations, et tiendront compte des besoins des pays en développement et des pays les moins avancés. »

Source : OMC, Aperçu général sur l'environnement : la relation entre les AEM et l'OMC - Le mandat de négociation de Doha concernant les AEM (http://www.wto.org/french/tratop_f/envir_f/envir_backgrnd_f/c5s3_f.htm) 
Tableau 5. Interdictions d'importation mentionnées dans les principaux AEM

\begin{tabular}{|l|l|}
\hline Intitulé de l'AEM: & Interdictions mentionnées \\
\hline $\begin{array}{l}\text { Convention internationale pour la protection des } \\
\text { végétaux }\end{array}$ & $\begin{array}{l}\text { Les parties peuvent interdire l'importation de } \\
\text { certains végétaux et produits végétaux dans le but } \\
\text { de prévenir la dissémination et l'introduction } \\
\text { d'organismes nuisibles aux végétaux et produits } \\
\text { végétaux. }\end{array}$ \\
\hline $\begin{array}{l}\text { Convention internationale pour la conservation des } \\
\text { thonidés de l'Atlantique }\end{array}$ & $\begin{array}{l}\text { Des recommandations peuvent appeler à } \\
\text { l'instauration de mesures de restriction du } \\
\text { commerce, de nature non discriminatoire, et } \\
\text { cohérentes avec leurs obligations internationales, en } \\
\text { ce qui concerne les espèces en question. }\end{array}$ \\
\hline $\begin{array}{l}\text { Convention sur le commerce international des } \\
\text { espèces de faune et de flore sauvages menacées } \\
\text { d'extinction }\end{array}$ & $\begin{array}{l}\text { Peut interdire les échanges commerciaux } \\
\text { internationaux de certains spécimens. }\end{array}$ \\
\hline $\begin{array}{l}\text { Protocole de Montréal relatif à des substances qui } \\
\text { appauvrissent la couche d'ozone }\end{array}$ & $\begin{array}{l}\text { Interdiction d'importation de certaines substances } \\
\text { réglementées }\end{array}$ \\
\hline $\begin{array}{l}\text { Convention de Bâle sur le contrôle des mouvements } \\
\text { transfrontières de déchets dangereux et de leur } \\
\text { élimination }\end{array}$ & $\begin{array}{l}\text { Les parties peuvent exercer le droit d'interdire } \\
\text { l'importation de déchets dangereux ou d'autres } \\
\text { déchets. }\end{array}$ \\
\hline $\begin{array}{l}\text { Convention de Stockholm sur les polluants } \\
\text { organiques persistants }\end{array}$ & $\begin{array}{l}\text { Les parties interdisent les importations des } \\
\text { substances chimiques citées. }\end{array}$ \\
\hline
\end{tabular}

Source : OMC, Matrice des mesures commerciales prises au titre de divers accords environnementaux multilatéraux, WT/CTE/W/160/Rev.2TN/TE/S/5, 25 avril 2003

56. Les interdictions sont aussi parfois appliquées pour atteindre des objectifs de politique étrangère. Cela peut se faire de manière unilatérale ou dans le cadre d'accords multilatéraux, comme les résolutions du Conseil de sécurité des Nations Unies. Surtout, les pays développés interdisent aussi l'importation de certains produits pour des raisons humanitaires. Ainsi, l'importation de produits fabriqués par des détenus, par des enfants ou dans le cadre du travail forcé est interdite aux États-Unis. Une loi récente de l'UE, qui interdit la vente et l'importation de produits cosmétiques contenant des ingrédients testés sur des animaux, en est un autre exemple. L'interdiction frappant la plupart des catégories entrera en vigueur en 2009. Les périodes de transition sont nécessaires pour permettre aux entreprises de mettre au point d'autres procédures de test.

57. Bon nombre de pays interdisent également certains produits dans le but de protéger la moralité publique. Il ressort des examens commerciaux que les produits interdits pour cette raison diffèrent selon les pays. Par exemple, bon nombre de pays musulmans interdisent une plus grande gamme de produits que d'autres pays pour des motifs culturels et religieux (Indonésie, Malaisie, Bahreïn, Mauritanie, Maldives, Algérie, etc.). Ils prohibent l'importation de documents offensants pour l'Islam, et interdisent ou restreignent durement l'importation de boissons alcoolisées, de porcs et de viande de porc. Un petit groupe de pays proscrit par ailleurs l'importation de bandits manchots afin de protéger la moralité publique (Turquie, Thaillande, Salvador, Pakistan et Chine). 
58. Les rapports sur les EPC examinés par le Secrétariat indiquent que le nombre de produits assujettis à des interdictions pour des raisons autres qu'économiques, notamment pour des raisons liées à l'environnement, à la santé et à la sécurité, a augmenté ces dernières années. Cela dit, il apparaît qu'ils ne représentent pas une part importante des échanges internationaux à ce jour, et la conformité de ces mesures aux accords de l'OMC n'est par ailleurs généralement pas mise en doute. Les interdictions pesant sur l'importation de biens usagés semblent constituer une exception à cette observation, comme nous le verrons en détail plus loin. Un examen plus approfondi visant à déterminer si les mêmes mesures s'appliquent aux produits nationaux permettrait de vérifier la légitimité des interdictions auxquelles ces produits sont assujettis. Les données disponibles dans le cadre de la présente étude ne permettent cependant pas de procéder à cette évaluation.

\section{Interdictions d'importation appliquées aux biens usagés}

59. Un examen plus attentif montre que les restrictions quantitatives, les prohibitions notamment, jouent un rôle important dans les échanges internationaux de biens d'équipement et de consommation usagés (vêtements, matériel et véhicules) du fait que de nombreux pays élaborent leur politique commerciale de manière à établir une discrimination à l'encontre des produits d'occasion. Ce marché présente un potentiel intéressant et offre des débouchés commerciaux au sujet desquels les informations sont toutefois rares; de plus, les restrictions appliquées à ce type d'importation varient généralement d'un produit à l'autre et selon le pays de destination.

60. Beaucoup de pays limitent l'importation de biens usagés. Les EPC d'un tiers environ des pays examinés signalent des restrictions d'importation sur certains d'entre eux. La fréquence de ces restrictions et d'autres sortes de barrière au commerce dans ces domaines est d'autant plus patente que la base de données de l'UE sur l'accès aux marchés, établie d'après les informations communiquées par les milieux d'affaires, signale un nombre très important de cas où l'importation de produits d'occasion est interdite, les automobiles essentiellement. L'examen d'autres sources d'information livre un panorama similaire.

61. De fait, il a été observé que les biens usagés constituent une exception négligée à la libéralisation généralisée des échanges à laquelle on a assisté ces dernières années. ${ }^{27}$

\section{Produits assujettis à des restrictions}

62. Il ressort de l'examen des EPC et d'autres rapports que les marchandises d'occasion les plus souvent assujetties à des restrictions quantitatives sont les automobiles et les pièces de rechange, la machinerie, les tissus et les instruments médicaux.

63. Les mesures appliquées sont très souvent des prohibitions d'importation. Il peut s'agir d'interdictions absolues ou des prohibitions assujetties à des conditions précises. Dans le cas des automobiles, par exemple, les critères pertinents portent notamment sur l'ancienneté, les normes environnementales, etc. Comme indiqué dans les rapports, certains pays font également appel à des procédures de licences non automatiques rigoureuses qui constituent en fait des interdictions.

64. Ces restrictions sont couramment appliquées par les pays en développement, mais les pays développés établissent aussi parfois une discrimination à l'encontre des biens d'occasion. Beaucoup de pays latino-américains, africains et asiatiques n'autorisent pas l'importation de certains produits usagés. Il s'agit entre autres de pays dotés de vastes marchés, comme le Brésil, la Chine et l'Inde, qui appliquent des régimes d'importation rigoureux interdisant une large gamme de produits. 27 Danilo Pelletiere et Kenneth A. Reinert, Used automobile protection and trade: Gravity and ordered probit
analysis, School of Public Policy, George Mason University, Washington, D.C. 25 août 2003 . 
Tableau 6. Incidence des interdictions d'importation sur les biens usagés.

\begin{tabular}{|c|c|c|c|c|c|c|}
\hline & Automobiles & Pneus & Vêtements & Machinerie & $\begin{array}{l}\text { Matériel } \\
\text { électrique }\end{array}$ & $\begin{array}{l}\text { Matériel } \\
\text { médical }\end{array}$ \\
\hline Argentine & & $\mathrm{x}$ & $\mathrm{x}$ & & & $\mathrm{X}$ \\
\hline Bolivie & $\mathrm{x}$ & & & & & \\
\hline Brésil & $\mathrm{x}$ & & $\mathrm{x}$ & $\mathrm{x}$ & & \\
\hline Brunei & $\mathrm{x}$ & & & & & \\
\hline Canada & $\mathrm{x}$ & & & & & \\
\hline Chili & $\mathrm{x}$ & & & & & \\
\hline $\begin{array}{l}\text { Rép. } \\
\text { dominicaine }\end{array}$ & $\mathrm{x}$ & & $\mathrm{x}$ & & $\mathrm{x}$ & \\
\hline Équateur & $\mathrm{x}$ & $\mathrm{x}$ & $\mathrm{x}$ & & & \\
\hline Égypte & $\mathrm{x}$ & & & & & \\
\hline Ghana & $\mathrm{x}$ & & & & & \\
\hline Inde & $\mathrm{x}$ & & & & & \\
\hline Israël & & & $\mathrm{x}$ & & & \\
\hline Maldives & $\mathrm{x}$ & & & & & \\
\hline Mozambique & & $\mathrm{x}$ & $\mathrm{x}$ & & & \\
\hline Nicaragua & $\mathrm{x}$ & & & & & \\
\hline Nigeria & $\mathrm{x}$ & & & & $x(1)$ & \\
\hline Pakistan & & & & $\mathrm{x}$ & & \\
\hline Pérou & $\mathrm{x}$ & $\mathrm{x}$ & $\mathrm{x}$ & & & \\
\hline Salvador & $\mathrm{x}$ & & & & & \\
\hline Sri Lanka & & & & $\mathrm{x}$ & & \\
\hline Tanzanie & & & $\mathrm{x}$ & & & \\
\hline Thaillande & $\mathrm{x}$ & & & & & \\
\hline Venezuela & $\mathrm{x}$ & $\mathrm{x}$ & $\mathrm{x}$ & & & \\
\hline
\end{tabular}

(1) Réfrigérateurs, climatiseurs, compresseurs

Source : établi à partir des Examens des politiques commerciales de l'OMC, 1999 - 2004, de la base de données MAD de l'UE (à compter de 2004), et des rapports de l'USTR (2003).

\section{Justifications de ces mesures}

65. La santé, la sécurité et la protection de l'environnement sont les raisons le plus souvent invoquées par les autorités pour justifier ces interdictions. Or, les études disponibles laissent entendre que des motifs économiques interviennent également. Ces mesures sont motivées à la fois par la volonté de protéger les producteurs (ou les distributeurs) nationaux de nouveaux produits vis-à-vis de la concurrence de produits usagés ou reconstruits à bas prix pour éviter de devenir la « décharge » des pays à revenu élevé, et par celle de pousser l'industrie vers la «frontière technologique» et d'éviter l'emploi de technologies «obsolètes $»^{28}$.

66. Des observations ponctuelles et des reportages de la presse locale ont ainsi montré comment les revendications de l'industrie textile locale ont abouti à l'interdiction d'exportation de tissus usagés dans plusieurs pays africains. Par ailleurs, des études empiriques portant sur les politiques commerciales en

${ }^{28}$ Voir Giorgio Barba Navaretti, Isidro Soloaga et Wendy Takacs, When Vintage Technology Makes Sense: matching Imports to Skills, Banque mondiale, Washington 1998. Pelletiere et Reinert ont analysé les données relatives aux restrictions pesant sur les importations d'automobiles d'occasion dans de nombreux pays et conclu que la présence d'une industrie nationale est un prédicteur important d'une politique restrictive. 
Amérique latine indiquent que les restrictions quantitatives sur les automobiles d'occasion résultent en grande partie des pressions exercées par les producteurs et distributeurs nationaux de véhicules neufs. ${ }^{29}$

\section{Le cas des véhicules et des pièces automobiles}

67. Les données statistiques sur l'ampleur du marché mondial et les flux commerciaux relatifs aux automobiles d'occasion sont rares. Si l'on suppose qu'une automobile a en moyenne quatre propriétaires au cours de son existence, le marché de l'automobile d'occasion est manifestement nettement plus important que celui des véhicules neufs. Les véhicules d'occasion expédiés à l'étranger par le premier exportateur dans ce domaine, le Japon, devaient représenter le montant record de 1 million de dollars en 2003. Les chiffres présentés au tableau 7 proviennent de différents bulletins d'information et d'autres rapports et ont pour seul objectif de donner, pour certains pays, une idée approximative du nombre d'automobiles d'occasion importées et du poids de ce marché. Du fait que la croissance des marchés de plus en plus saturés des pays développés diminue, l'accès aux marchés étrangers suscite un intérêt grandissant. $^{30}$

Tableau 7. Importations d'automobiles d'occasion dans certains pays

\begin{tabular}{|l|l|l|l|}
\hline Pays & Année & $\begin{array}{l}\text { Nombre } \\
\text { d'automobiles } \\
\text { importées }\end{array}$ & \% du marché total \\
\hline Australie & 1999 & 25000 & - \\
\hline Bulgarie & 2001 & 120000 & 90 \\
\hline République tchèque & 1999 & 145000 & 42 \\
\hline Chypre & 2000 & 10000 & 60 \\
\hline Estonie & 2000 & 12000 & 35 \\
\hline Kenya & 1999 & 30000 & - \\
\hline Nouvelle-Zélande & 2000 & 116000 & 70 \\
\hline Philippines & 2001 & 50000 & 39 \\
\hline Pologne & 1999 & 2000000 & 20 \\
\hline Russie & 2001 & 360000 & 80 \\
\hline Royaume-Uni & 1998 & 60000 & - \\
\hline
\end{tabular}

Source : adaptation de Sofronis K. Clerides, The Welfare Effects of Trade Liberalisation: Evidence from Used Automobiles. Université de Chypre et Université de Yale, avril 2003.

68. Les sources de données examinées pour les besoins de la présente étude indiquent que le commerce international d'automobiles d'occasion fait particulièrement souvent l'objet de restrictions quantitatives. Les mesures le plus couramment appliquées sont les interdictions assorties d'exceptions très précisément définies dans certaines circonstances. Certains pays font en outre appel aux licences non automatiques ou à des droits élevés pour décourager l'importation, mais le recours aux interdictions est plus fréquent que celui à d'autres méthodes. Dans les cas où l'importation d'automobiles d'occasion est autorisée sous certaines conditions, celles-ci ont souvent trait à l'ancienneté du véhicule, qui varie entre trois et cinq ans. Beaucoup de pays n'appliquent de restrictions qu'à certains types de véhicules (voitures

\footnotetext{
${ }^{29}$ Voir Pelletiere et Reinert (2002), op. cit.

30 «How Japan's second-hand cars make their way to Third Word », The Wall Street Journal, 8 janvier 2004.
} 
particulières, motocyclettes, camions, minibus et bus de capacité inférieure ou supérieure à une capacité donnée).

69. Un tiers des pays ayant fait l'objet d'un EPC au cours des cinq années écoulées ont assujetti l'importation de véhicules d'occasion à des interdictions. Celles-ci ne portent pas sur les ventes, mais sur les importations. La vente de véhicules d'occasion nationaux est autorisée sur le marché local.

70. Ce sont les pays latino-américains ${ }^{31}$ et africains qui font le plus souvent appel à des interdictions. Quelques pays asiatiques y ont aussi recours. Plusieurs pays d'Europe centrale (République tchèque et Hongrie par exemple) ont également interdit l'importation d'automobiles dépassant un âge donné dans les années 90. Ces interdictions ont toutefois été remplacées, le plus souvent par un mécanisme de droits fondé sur des critères d'environnement et de sécurité. L'environnement, la santé et la sécurité sont les explications le plus souvent données à ces interdictions.

71. Beaucoup de pays essentiellement en développement limitent également l'importation de pièces d'occasion, reconstruites ou remises à neuf. ${ }^{32}$ Les pays latino-américains, notamment, les interdisent complètement. L'encadré 2 donne quelques exemples représentatifs des restrictions à l'importation pesant sur ces produits.

72. Dans beaucoup de pays en développement, il existe un vaste marché de pièces d'automobiles d'occasion qui s'explique par la tendance à allonger la vie utile des véhicules pour éviter l'achat d'un neuf. La croissance démographique des grandes villes et la faiblesse des revenus sont les facteurs qui stimulent la demande de véhicules d'occasion et de pièces automobiles reconstruites, remises à neuf et/ou d'occasion. À l'inverse, le fort pourcentage de véhicules nouveaux sur la route et l'offre élevée de pièces neuves à faible coût ont tendance à freiner le développement du marché des pièces d'occasion.

73. La libéralisation des échanges est un autre facteur qui favorise la demande. C'est ce que montre le cas de la Jamaïque, qui a libéralisé son secteur automobile en 1993. Depuis lors, les importations d'automobiles d'occasion ont rapidement augmenté. Alors qu'en 1993 près de 12000 des 19000 véhicules importés étaient neufs, ce n'était plus le cas que de 6000 automobiles sur 26000 en 1994. Cette tendance s'est poursuivie jusqu'en 1998, date à laquelle le marché des automobiles importées a commencé à donner des signes de saturation. ${ }^{33}$

\footnotetext{
${ }^{31}$ La forte incidence des mesures non tarifaires sur les importations de véhicules en Amérique latine est confirmée par l'article de D.Pelletiere et K.A. Reinert (2002), «The Political Economy of Used Automobile Protection in Latin America »", The World Economy, Vol. 25, n 7, pp. 1019-1037.

${ }^{32}$.On entend généralement par pièces d'occasion des pièces qui ont été retirées d'un véhicule et sur lesquelles aucune opération à valeur ajoutée n'a été effectuée, si ce n'est le nettoyage. À l'inverse, des pièces reconstruites ou remises à neuf sont des pièces qui ont été entièrement refaites conformément aux spécifications d'usine d'origine. Cela dit, dans la pratique, les pays les assimilent souvent à des pièces « usagées ». Le marché des pièces reconstruites a été estimé à entre 60 et 70 milliards de dollars de ventes à l'échelon mondial. Département américain du commerce, Office of Automotive Affairs, International Trade Administration. Compilation of Foreign Remanufacturing Parts Import Restrictions, octobre 1999. 88.

${ }^{33}$ Ibid., 43.
} 


\section{Encadré 2. Restrictions aux importations de pièces automobiles reconstruites/remises à neuf.}

Au Brésil, les importations de pièces reconstruites ne sont autorisées que lorsque l'opération est réalisée par le fabriquant d'origine. Les pièces reconstruites et remises à neuf sont assimilées à des pièces usagées.

Au Chili, l'importation de véhicules d'occasion est interdite, mais celle de pièces automobiles reconstruites, remises à neuf et/ou d'occasion est autorisée. Les autorités douanières craignent toutefois que les pièces importées ne servent à assembler des automobiles d'occasion, ou des portions substantielles d'automobiles d'occasion, et ce genre de produits fait généralement l'objet d'un examen minutieux en douane.

En Chine, l'importation de pièces automobiles d'occasion est interdite. Dans de rares cas, comme les pièces d'automobiles anciennes, des autorisations d'importation spéciales sont accordées et l'importateur doit soumettre une demande précisant l'utilisation envisagée et le motif de l'importation.

En Israël, les importations de pièces automobiles reconstruites, remises à neuf et/ou d'occasion sont limitées et autorisées par le Ministère des transports au cas par cas. S'agissant de composants automobiles essentiels, comme les systèmes de direction et de freinage, le Ministère autorise uniquement l'importation de pièces neuves, celles-ci devant être importées par un fabricant préagréé.

En Afrique du Sud, l'importation de pièces automobiles reconstruites, remises à neuf et/ou d'occasion est limitée aux moteurs à essence supérieurs à $3000 \mathrm{cc}$, aux moteurs diesel supérieurs à $3500 \mathrm{cc}$, aux transmissions pour automobiles et microbus, et à toute autre pièce non fabriquée à l'origine dans le pays. Toutes font l'objet d'une évaluation au cas par cas du Département du commerce et de l'industrie.

Dans les Émirats arabes unis, l'importation de pièces automobiles reconditionnées et d'occasion est interdite, à moins qu'elle ne soient reconditionnées par le fabricant d'origine. Le revendeur n'a pas le droit d'arguer que la pièce concernée est identique à la pièce d'origine, et le même traitement s'applique aux pièces automobiles reconstruites et d'occasion.

Source : Département américain du commerce, Office of Automotive Affairs, International Trade Administration. Compilation of Foreign Remanufacturing Parts Import Restrictions, octobre 1999.

74. Les exportateurs de ces marchandises sont confrontés à des interdictions ou à d'autres restrictions quantitatives dans les pays en développement principalement. Seuls deux des 20 pays de l'OCDE examinés dans le cadre d'une étude de 1999 portant sur les restrictions commerciales relatives à l'accès au marché des pièces automobiles appliquaient de telles mesures, et un seul interdisait leur importation. ${ }^{34}$

75. Les pneus appartiennent à la catégorie des véhicules et pièces automobiles qui sont soumis à des interdictions d'importation dans d'assez nombreux pays, notamment en Amérique latine et en Afrique. Dans la plupart des cas, l'interdiction est totale et justifiée par des motifs liés à la sécurité et à l'environnement.

\footnotetext{
${ }^{34}$ D. Pelletiere et K.A. Reinert (2002), op. cit.
} 


\section{Autres secteurs}

76. Les interdictions d'importation de vêtements usagés sont aussi courantes. Les exportations mondiales dans ce domaine se sont élevées à 990 millions de dollars en 2001, soit un faible pourcentage des exportations de vêtements neufs, évaluées à 146 milliards de dollars; cette comparaison est cependant quelque peu trompeuse, car il convient de tenir compte de la très faible valeur des vêtements usagés (0,73 dollar par kilogramme environ) ${ }^{35} \mathrm{Ce}$ sont essentiellement les pays africains et quelques pays latinoaméricains et asiatiques à faible revenu (mais aussi la Chine) qui appliquent des interdictions. Celles-ci sont généralement absolues et justifiées par des motifs sanitaires. Certains pays (l'Afrique du Sud par exemple) n'autorisent l'entrée de vêtements usagés que s'il s'agit de dons humanitaires.

77. Plusieurs pays imposent des interdictions conditionnelles à l'importation de machinerie d'occasion, pour des raisons de sécurité et d'environnement. C'est le cas, principalement, de certains pays asiatiques et latino-américains. Les interdictions absolues sont rares ; la plupart des pays préfèrent imposer des conditions exigeant que les marchandises concernées respectent des normes techniques rigoureuses.

78. Enfin, il ressort des rapports que certains pays choisissent d'interdire l'importation d'autres catégories de biens d'occasion : matériel médical (domaine dans lequel la Chine, l'Égypte, le Koweït, la Syrie et la Thaïlande appliquent des interdictions absolues), ${ }^{36}$ dispositifs électroniques (République dominicaine), réfrigérateurs, climatiseurs et compresseurs (Nigeria).

79. Une tendance semble se dessiner en faveur de l'abandon des interdictions proprement dites, tout du moins dans le cadre des accords de libre échange bilatéraux et régionaux. Un examen sommaire de quelques-uns des principaux accords commerciaux régionaux montre que certains d'entre eux traitent la question du commerce des biens usagés

80. Ainsi, dans le cadre de l'ALENA, le Mexique a accepté de lever progressivement, sur dix ans, l'embargo sur les véhicules d'occasion (véhicules légers, autobus et poids lourds) qui respectent les règles d'origine de l'Accord. Autrement dit, l'interdiction sera complètement abolie en 2019. ${ }^{37}$ Par suite de l'accord de libre-échange Union européenne-Mexique, l'Union européenne bénéficiera des mêmes avantages, en termes d'accès au marché des véhicules d'occasion, que ceux dont bénéficient les États-Unis et le Canada en vertu de l'ALENA, à condition que les véhicules respectent les règles d'origine de l'Accord. $^{38}$

\footnotetext{
${ }^{35}$ Source : base de données COMTRADE des Nations Unies.

${ }^{36}$ Selon le rapport Global ImportRegulations for PreOwned (Used and Refurished) Medical Devices rédigé en 2002 par le Département américain du commerce. L'étude a examiné les informations disponibles sur les réglementations applicables au matériel médical d'occasion sur 99 marchés. Il en ressort que 78 d'entre eux autorisent l'importation sans restriction de matériel médical usagé ou rénové. Le rapport relève toutefois que pour plusieurs de ces marchés, il convient plutôt de dire qu'aucune restriction n'est signalée puisque les rapports disponibles ne mentionnent pas de restrictions, ou indiquent simplement que les autorités autorisent l'importation de matériel d'occasion en général, sans mentionner spécifiquement le matériel médical. Les pays qui appliquent des restrictions plus ou moins rigoureuses sont l'Afrique du Sud, l'Argentine, le Brésil, le Canada, la Colombie, la Croatie, l'Inde, le Japon, la Corée du Sud, la Moldavie, l'Ouzbékistan, le Pakistan, le Pérou, la Turquie et le Vietnam. Les cinq pays qui les interdisent sont la Chine, la Syrie, l'Égypte, la Thaïlande et le Koweït.

${ }^{37}$ Zone de libre-échange des Amériques (ZLEA): Key automotive markets and issues, version du 9 mai 2002, ITA, Département américain du commerce, 9 mai 2002, p. 55. http://www.ita.doc.gov/td/auto/FTAAAuto.pdf

${ }^{38}$ Ibid., 56
} 
81. Cela dit, il existe aussi des accords commerciaux régionaux qui ne prévoient aucune libéralisation de ce marché. Ainsi, le MERCOSUR et l'Accord de libre-échange États-Unis-Chili prévoient des interdictions illimitées sur les automobiles d'occasion. ${ }^{39}$

82. Les nombreuses restrictions à l'importation qui pèsent sur le commerce international des biens usagés soulèvent plusieurs questions susceptibles d'intéresser les décisionnaires et les négociateurs.

83. Pourquoi les produits usagés sont-ils traités différemment des produits neufs dans les cas où les uns comme les autres présentent des risques en matière de sécurité, de santé ou de protection de l'environnement? Dans les nombreux cas où des objectifs réglementaires nationaux sont en cause, les biens usagés devraient probablement être assujettis aux mêmes mesures que les produits neufs. Les règlements portant sur l'importation des premiers devraient donc être identiques à ceux appliqués aux seconds. Dans les cas où la sécurité est en cause, par exemple, l'importation de biens nouveaux et usagés pourrait être autorisée sous réserve de satisfaireaux mêmes obligations en matière de normes.

84. Même s'il existe des raisons valables d'établir une distinction entre marchandises neuves et usagées (par exemple parce que les secondes ne sont généralement pas assorties d'une garantie, ou bien d'une garantie limitée), la question peut se poser de savoir si l'interdiction d'importation de biens usagés se justifie dans le cas où l'objectif politique est réalisable par d'autres moyens moins restrictifs pour le commerce. Les biens anciens (usagés) ou reconstruits pourraient simplement être admis dans le pays pour être soumis à un examen minutieux visant à déterminer s'ils sont conformes aux différentes normes en matière d'environnement, de sécurité et autres. Des dispositifs d'inspection et de certification au regard de normes et, le cas échéant, le recours à des autorisations d'importation sont des méthodes applicables, moins restrictives pour le commerce, et que certains pays ont déjà adoptées.

85. L'argument de la protection de l'environnement pour interdire l'importation de marchandises usagés mérite peut-être un examen plus approfondi. Le recyclage des produits et l'allongement du cycles de vie de certains d'entre eux, comme les vêtements et les pièces automobiles, semblent motivés par le souci d'appliquer une bonne politique environnementale. Au Japon, par exemple, il apparaît que les autorités et les groupes de défense de l'environnement attirent l'attention des consommateurs et du public sur leur responsabilité envers la protection des ressources naturelles et les sensibilisent aux avantages liés à l'utilisation de pièces reconstruites ou d'occasion par rapport aux pièces neuves.

86. L'un des arguments évoqués pour limiter l'importation de marchandises d'occasion est le plus grand risque de fraude que présente ce commerce. Les interdictions d'importation et autres restrictions quantitatives présentent néanmoins des inconvénients analogues. Elles favorisent par exemple le fonctionnement d'un marché parallèle qui échappe à la surveillance réglementaire.

\section{Autres types de restrictions quantitatives}

87. La présente étude s'est également penchée sur l'incidence des références à trois autres types de mesures inscrites par l'OMC dans la catégorie des restrictions quantitatives, à savoir les « restrictions quantitatives appliquées par le biais d'activités de commerce d'État», les « réglementations concernant les mélanges » et les «prix minimum déclenchant une restriction quantitative ». Elle en a conclu que les références à ces mesures sont sensiblement moins fréquentes que celles à d'autres formes de restrictions quantitatives, comme les licences automatiques et non automatiques, les prohibitions et les contingents.

\footnotetext{
${ }^{39}$ Automotive Provisions Report, Office of Automotive Affairs, ITA, Département américain du commerce, disponible sur le site : http://www/ita.doc.gov/auto,
} 
88. Les bases de données et les documents commerciaux examinés pour les besoins du présent rapport ne mentionnent pas de prix minimum déclenchant une restriction quantitative.

89. Les entreprises commerciales d'État, telles que définies par l'OMC, sont des «entreprises gouvernementales et non gouvernementales, y compris les offices de commercialisation, qui exportent et/ou importent des marchandises. ${ }^{40}$ L'article XVII du GATT de 1994 est la principale disposition traitant de ces entreprises et de leurs activités. Il stipule que les Membres sont tenus de notifier leurs entreprises commerciales d'État à l'OMC chaque année. ${ }^{41}$

90. Les activités de commerce d'État soulèvent de nombreux problèmes, dont le recours aux restrictions quantitatives n'est qu'un parmi d'autres. Les règles de l'OMC ont pour objet de veiller à ce que les entreprises commerciales d'État ne servent pas à appliquer des mesures non conformes à l'OMC. Les obligations de fond des Membres en vertu des règles régissant le commerce d'État sont les suivantes : nondiscrimination, généralement désignée sous le nom de traitement de la «nation la plus favorisée » ou «NPF»; absence de restrictions quantitatives; maintien de la valeur des avantages tarifaires et transparence. $^{42}$

91. Il ressort de l'examen des EPC et d'autres sources que les problèmes relatifs à la concurrence (situations de monopole), à la transparence, à la recherche de rentes et à la discrimination sont les plus souvent mentionnés en ce qui concerne les régimes de commerce d'État. L'examen rapide des sources de données a indiqué que les références à l'existence de restrictions quantitatives dans le cadre des activités de commerce d'État sont très rares, à ces quelques exceptions près :

- Au Gabon, l'entreprise qui détient le monopole du sucre interdit l'importation de sucre sous toutes ses formes.

- Au Brunei, l'importation de sucre et de riz est assujettie à des restrictions et à des licences, et effectuée directement par l'État.

- Au Bangladesh, l'importation du sucre et de sel est généralement interdite, sauf en cas de pénurie, auquel cas deux entreprises publiques en sont les importateurs exclusifs.

\footnotetext{
${ }^{40} \mathrm{OMC}$, The regulation of State Trading System under the WTO System, disponible sur le site : http://www.wto.org/english/tratop_e/statra_e/statrad.htm

${ }^{41}$ L'étude conduite sous la supervision de l'OMC et les examens nationaux ont révélé que plusieurs pays, en développement pour la plupart, disposent de régimes commerciaux d'État qui couvrent un large éventail de produits. Parmi les grands pays membres de l'OMC, par exemple, la Chine, l'Inde, le Pakistan et l'Indonésie sont des pays où l'État intervient dans toute une gamme d'activités commerciales. Les produits concernés sont le plus souvent des produits agricoles de base (riz, céréales, sucre, sel, coton, etc.), certains pays exportant par ailleurs des produits industriels et des matières premières (le plus souvent des carburants, des fertilisants, des produits sidérurgiques, du matériel militaire, etc.) uniquement par l'intermédiaire des entreprises publiques. L'État indonésien, par exemple, se réserve des droits exclusifs sur l'importation de nombreux produits : boissons alcoolisées, sucre, textiles, certains produits sidérurgiques, etc. On trouve aussi dans bon nombre de pays développés des secteurs ou ds catégories de produits qui entrent dans le cadre des activités de commerce d'État. Au Japon, ce commerce porte ainsi sur plusieurs produits agricoles. En Corée, différents produits agricoles et sidérurgiques, de même que quelques services, entrent dans ce cadre. Parallèlement, plusieurs pays se sont efforcés de libéraliser leurs entreprises commerciales d'État. La Chine, par exemple, à l'occasion de son accession à l'OMC, a mis en œuvre la libéralisation requise des droits commerciaux des enteprises chinoises.
}

42 OMC, the regulation of State Trading System under the WTO System, disponible sur le site : http://www.wto.org/english/tratop_e/statra_e/statrad.htm 
92. Les réglementations concernant les mélanges spécifient la quantité de produits fabriqués dans le pays qu'un importateur doit acheter pour une quantité donnée d'importations. Ces modalités sont appliquées dans quelques pays en développement, essentiellement dans le cadre de marchés publics. On citera les cas suivants :

- En Thaïlande, la loi nationale stipule que tous les marchés conclus par des organismes et entreprises publics et portant sur des importations d'une valeur supérieure à un montant donné doivent s'accompagner d'opérations de contre-achats représentant la moitié au moins du montant du marché public.

- La International Trade Corporation (PITC) des Philippines encourage l'intégration d'obligations de contre-achats ou de compensation dans les projets de marchés publics d'une valeur minimale de 1 million de dollars.

- L'EPC d'Israël montre que durant la période couverte (1994-1999), en vertu de la loi israélienne, tout marché public d'un montant supérieur à NIS 1,5 million doit comprendre une clause de « coopération industrielle » obligeant les fournisseurs étrangers à acheter des biens ou services israéliens d'un montant équivalent à $35 \%$ de celui du contrat. Les fournisseurs étrangers peuvent aussi investir dans les industries locales.

\section{Quatrième partie.}

\section{Conséquences économiques et commerciales des restrictions quantitatives}

93. Cette section présente une brève synthèse conceptuelle des conséquences commerciales et économiques des restrictions quantitatives, accompagnée de données quantitatives dégagées des études réalisées dans ce domaine. Les études économiques indiquent que lorsque les restrictions quantitatives sont motivées par le souhait de protéger des produits nationaux particuliers de la concurrence de produits étrangers, elles imposent des coûts nettement supérieurs aux avantages, pour les pays importateurs comme pour les pays exportateurs. Il est largement reconnu qu'elles nuisent davantage à l'efficience commerciale et économique que les droits de douane; en effet, dans le cas des droits de douane, les ressources sont allouées par le biais des mécanismes des prix tandis que dans celui des contingents, elles le sont par voie administrative, par l'État. Malgré ces retombées défavorables, les pouvoirs publics n'en continuent pas moins de recourir souvent aux restrictions quantitatives qui, si elles sont moins fréquentes aujourd'hui, existent encore. Du point de vue des pays importateurs, les contingents sont parfois plus intéressants que les droits de douane, parce que l'effet d'un droit donné sur le volume des importations est incertain dans la mesure où il dépend de l'élasticité de la demande et de l'offre nationales du produit.

94. S'agissant des conséquences économiques, on observe d'abord que les prohibitions et les contingents détériorent en général les termes de l'échange pour les pays exportateurs et diminuent leur bien-être économique. Dans le même temps, les contingents permettent à un petit nombre d'exportateurs de réaliser des « rentes de contingentement » ou des bénéfices plus élevés étant donné les prix supérieurs qu'ils peuvent appliquer à leurs produits. Comme l'explique l'encadré 3, la façon dont les autorités administrent les contingents détermine qui sont les bénéficiaires de ces rentes.

95. Ensuite, les restrictions quantitatives créent un effet de substitution des importations qui nuit aux consommateurs des pays importateurs. La pénurie de produits importés provoquée par cette politique a pour conséquence inévitable de porter le prix des produits sur le marché national au montant maximum que les consommateurs sont disposés à payer. Ceux-ci, industries en aval comprises, supportent le coût économique lié à la perte de l'accès à des produits concurrents meilleur marché puisqu'ils disposent d'un choix de produits plus limité à des prix plus élevés. La perte de bien-être tient également au fait que 
contrairement aux droits de douane, les prohibitions et, parfois, les contingents, ne produisent pas de recettes pour l’État. ${ }^{43}$

\section{Encadré 3. Les effets des différents modes d'allocation de contingents}

La méthode retenue pour administrer un contingent peut considérablement influencer les effets de celui-ci. Celle que la plupart des économistes privilégieraient, mais que les autorités n'utilisent que rarement, consiste à mettre les contingents aux enchères. Elle revient pratiquement à établir un droit égal au prix de la licence puisque, d'une part, elle a pour effet de porter le prix national à un niveau supérieur au prix mondial et, d'autre part, autorise les autorités à percevoir la différence sous forme de recettes (rente de contingentement).

Une autre méthode consiste à allouer gratuitement des droits pour l'importation de quantités fixes entre les entreprises importatrices. Une fois cette allocation effectuée, l'écart entre le prix national et le prix sur le marché mondial revient aux entreprises sous forme de rente pure et simple. Si les droits sont répartis entre un nombre suffisamment élevé d'entreprises, celles-ci se concurrenceront sur le marché national et finiront par appliquer un prix concurrentiel unique. Celui-ci sera toutefois suffisamment supérieur au prix mondial pour équilibrer l'offre et la demande sur le marché national. Cette méthode s'apparente aussi à un mécanisme de droits de douane, si ce n'est qu'ici les «recettes » dérivant des mesures non tarifaires, ou rentes de contingentement, vont aux entreprises titulaires des droits d'importation.

Si l'allocation s'effectue selon des critères politiques, par exemple, les entreprises importatrices potentielles seront incitées à dépenser des ressources dans la lutte pour ces rentes, par exemple pour obtenir des licences sur le marché politique, en exerçant des pressions ou en recourrant à tout autre mécanisme acceptable dans le pays. Si l'allocation s'effectue selon des critères économiques, les entreprises seront tentées d'exagérer le comportement qui doit servir d'indicateur. Ainsi, si les allocations doivent se fonder sur la taille de l'entreprise en termes de valeur comptable du capital social, les rentes de contingentement feront alors partie du rendement du capital des entreprises et celles-ci seront encouragées à surinvestir. Si les allocations se fondent sur les ventes nationales, et si les entreprises ont accès à une source d'approvisionnement nationale, elles augmenteront leurs approvisionnements nationaux au-delà même de ce que le prix national élevé indiquerait afin d'accaparer une part supérieure des rentes de contingentement.

Source : Alan V. Deardorff et Robert M. Stern, Measurement of Non-tariff Barriers, Document de travail du Département des affaires économiques, n 179, OCDE, 1997, 21-25.

96. Troisièmement, à court terme, les industries nationales dont les produits sont protégés tirent parfois profit des restrictions puisqu'elles peuvent éviter la concurrence étrangère et s'arroger ainsi une part de marché, augmenter leurs profits et protéger les emplois. A moyen et long termes, toutefois, les restrictions quantitatives ont un effet pernicieux sur l'industrie: elles découragent les entreprises d'améliorer leur productivité, ce qu'elles auraient dû faire si elles avaient été exposées à la concurrence sur le marché. Les industries nationales protégées de la concurrence étrangère par les restrictions quantitatives ont toutes les chances de devenir ou demeurer inefficaces et de ne pas relever ou maintenir la compétitivité des exportations à terme. A moins que les restrictions quantitatives ne soient clairement conçues comme des mesures temporaires subordonnées à des mesures de modernisation ou d'ajustement et à des gains de

\footnotetext{
${ }^{43}$ Il est également courant qu'un produit soit assujetti à la fois à un droit et à un contingent, de sorte qu'un droit est versé sur les unités admises dans le cadre du contingent.
} 
productivité suffisants, elles risquent fort, tant qu'elles restent en place, d'entraver le développement industriel et de nuire aux intérêts économiques du pays imposant les restrictions. ${ }^{44}$

97. Enfin, sur le plan mondial, les contingents amènent également une distorsion dans l'allocation des ressources. Ils sont toujours discriminatoires du fait qu'ils s'appliquent aux importations en provenance d'une source particulière. Très souvent, ces sources sont les fabricants à plus faible coût de ce produit dans le monde. Les contingents ne font donc pas que diminuer le volume des échanges ; il détournent également les échanges et, partant, la production, d'une source à faible coût à une source à coût élevé.

\section{Conclusions}

98. En raison de l'insuffisance et et de la qualité limitée des données disponibles, les enseignements que l'on peut obtenir de cette étude des EPC et d'autres analyses des profils d'utilisation des prohibitions et des contingents sont également limités et les conclusions provisoires.

99. La difficulté à obtenir des informations complètes et détaillées tient en partie au fait que le système de notification de l'OMC dans ce domaine ne semble pas être efficace. Tout d'abord, seuls quelques pays ont soumis des notifications et les détails fournis ainsi que l'accès à ces informations sont limités. Ensuite, les EPC eux-mêmes soulignent les difficultés à obtenir des données fiables auprès des autorités nationales. Enfin, tout examen de restrictions quantitatives est rendu difficile par l'évolution souvent rapide de ces mesures, probablement plus rapide que celle d'autres types de mesures non tarifaires.

100. Manifestement, le degré de transparence des systèmes de restrictions quantitatives est faible en comparaison à de nombreux autres aspects du régime commercial qui relèvent désormais de disciplines multilatérales. Aussi serait-il utile de trouver des moyens de renforcer les règles et la mise en œuvre du système de notification de l'OMC dans ce domaine.

101. Une tendance générale à la baisse est observable dans l'application de contingents et de prohibitions instaurés pour des motifs économiques. L'utilisation de ces mesures pour des motifs liés à la balance des paiements ou à la protection de certains secteurs a diminué. Qui plus est, plusieurs grands pays en développement - la Chine, l'Inde, le Bangladesh, l'Indonésie - ont récemment commencé à réduire progressivement le champ d'application de ces mesures. Les véhicules automobiles, les textiles et les équipements électriques sont les produits les plus couramment visés par ces restrictions. Un accord international sur les textiles et les vêtements conduira également à la suppression des restrictions commerciales dans cette branche, qui est aujourd'hui le dernier secteur touché par de nombreux contingentements.

102. Dans le même temps, des interdictions établies pour des motifs non économiques, notamment en vue de protéger l'environnement ainsi que la sécurité et la santé des personnes, sont en vigueur dans pratiquement tous les pays et, semble-t-il, de plus en plus nombreuses. L'incidence de ces mesures semble augmenter plus rapidement dans les pays développés, qui possèdent généralement une réglementation sociale plus rigoureuse. Les interdictions jouent un rôle particulièrement important dans les échanges de biens de consommation et d'équipement usagés. Elles portent en particulier sur l'importation de véhicules, de pièces automobiles et de machines d'occasion, ainsi que de vêtements usagés entre pays en

\footnotetext{
${ }^{44}$ En ce qui concerne les limites à l'utilisation des restrictions quantitatives aux fins de protection des industries embryonnaires et les effets de la recherche de rentes, voir par exemple, A. O. Krueger, « The political economy of the rent seeking society », American Economic .Review, Vol. 64, n 3, juin 1974. Par ailleurs, Bhagwati soutient que l'utilisation d'instruments budgétaires et monétaires est supérieur aux restrictions commerciales et aux mesures de contrôle des changes lorsqu'il s'agit de remédier aux problèmes de balance des paiements. Voir Jagdish N. Bhagwati, The New International Economic Order: the north-south debate, Cambridge, Mass. : MIT Press, 1978.
} 
développement et pays développés. Les conditions régissant ces interdictions semblent parfois obscures et, en soulevant certaines questions de fond, mettent en lumière un domaine qui mériterait peut-être d'être analysé plus en détail et éventuellement pris en compte dans le cadre des négociations sur l'accès aux marchés des produits non agricoles.

103. Lorsqu'elle est appliquée pour des motifs non économiques, une interdiction d'importation est la solution retenue pour faire en sorte que divers objectifs sociétaux soient atteints. Il importe de reconnaître la souveraineté des pays sur la réglementation, ainsi que leur droit à fixer et à poursuivre des objectifs réglementaires qui leur sont propres. De leur côté, il faut qu'ils tiennent compte des principes visant à assurer la qualité de la réglementation qui sont élaborés et prônés par l'OCDE. Ces principes comprennent des recommandations qui peuvent aider les gouvernements à élaborer des réglementations permettant d'atteindre leurs objectifs tout en favorisant l'ouverture des marchés. Dans le cas des interdictions, les pouvoirs publics doivent déterminer précisément si elles constituent les meilleurs solutions réglementaires ou s'ils peuvent choisir d'autres mesures permettant également d'atteindre les objectifs réglementaires fixés tout en ayant un effet de distorsion moins important sur l'économie ou sur d'autres objectifs de société. 


\section{BIBLIOGRAPHIE}

Bhagwati, J.N. (1978), The New International Economic Order: The North-South Debate, Cambridge, Mass.: MIT Press, 1978.

Clerides, S.K. (2003), « The Welfare Effects of Trade Liberalization: Evidence from Used Automobiles », www.econ.yale.edu/seminars/trade/tdw03/clerides-030512.pdf.

Commission européenne, Direction générale du Commerce, Base de données d'accès au marché, disponible sur le site http://mkaccdb.eu.int/

Finger J.M. et L. Schuknecht (1999), eMarket Access Advances and Retreats: the Uruguay Round and Beyonde, http://econ.worldbank.org/docs/959.pdf.

Goode, W. (2003), Dictionary of Trade Policy terms, WTO and Cambridge University Press.

« How Japan's second-hand cars make their way to Third Word », The Wall Street Journal, 8 January 2004.

Krueger, A.O. (1974), «The political economy of the rent seeking society », American Economic Review, Vol. 64, n 3, pp. 291-303.

Michalopoulos, C. (1999), « Trade Policy and Market Access Issues for Developing Countries », Banque mondiale, Washington, www.econ.worldbank.org/docs/940.pdf.

METI, Japon (2004), Report on the WTO Consistency and Trading Policies by Major Trading Partners, disponible sur le site http://www.meti.go.jp/english/report

Navaretti, G.B., I. Soloaga et W. Takacs (1998), « When Vintage Technology Makes Sense: Matching Imports to Skills », Banque mondiale, Washington, disponible sur le site http://econ.worldbank.org/docs/750.pdf.

OCDE, Libéralisation du commerce dans les industries textiles et de l'habillement, OCDE, Paris, 2003.

Pelletiere, D. et K.A. Reinert (2002), «The Political Economy of Used Automobile Protection in Latin America », The World Economy, Vol. 25, n 7, pp. 1019-1037.

Pelletiere, D. et K.A. Reinert (2003), « Used Automobile Protection and Trade: Gravity and Ordered Probit Analysis », School of Public Policy, George Mason University, Washington, D.C. 25 août 2003 (miméo).

Sofronis K. Clerides, The Welfare Effects of Trade Liberalisation: Evidence from Used Automobiles. University of Cyprus \&Yale University, avril 2003. 
The Wall Street Journal (2004), «How Japan's Second-Hand Cars Make Their Way to Third World », 8 janvier 2004.

Base de données COMTRADE des Nations Unies

U.S. Department of Commerce, Office of Automotive Affairs (1999), International Trade Administration. Compilation of Foreign Remanufacturing Parts Import Restrictions.

U.S. Department of Commerce (2002), Global Import Regulations for Pre-Owned (Used and Refurbished) Medical Devices.

U.S. Department of Commerce: Free Trade Area of the Americas (FTAA) (2002), « Key automotive markets and issues », version du 9 mai 2002 , disponible sur le site http://www.ita.doc.gov/td/auto/FTAAAuto.pdf.

US Department of Commerce, « Automotive Provisions Report, Office of Automotive Affairs », ITA, disponible sur le site http://www/ita.doc.gov/auto.

USTR, National Trade Estimate Report of Foreign Trade Barriers, 2003, disponible sur le site http://www.ustr.gov/reports/nte/2003/

OMC (1999), "Inde - Restrictions quantitatives à l'importation de prodpuits agricoles, textiles et industriels »-Rapport du groupe spécial, WT/DS90/R.

OMC (2003), Matrice des mesures commerciales prises au titre de divers accords environnementaux multilatéraux, WT/CTE/W/160/Rev.2TN/TE/S/5.

OMC, Bases de données sur l'environnement, 1996-2001

OMC, Examens des politiques commerciales, 1998-2004.

OMC (2003) et OMC (2004), Notifications d'obstacles non tarifaires. TN/MA/W/*.

OMC, Aperçu général sur l'environnement : la relation entre les AEM et l'OMC - Le mandat de négociation de Doha concernant les AEM ,

disponible sur le site http://www.wto.org/english/tratop_e/envir_e/envir_backgrnd_e/c5s3_e.htm

OMC, The regulation of State Trading System under the WTO System,

disponible sur le site http://www.wto.org/english/tratop_e/statra_e/statrad.htm 
ANNEXE 1.

\section{NOTIFICATIONS DE RESTRICTIONS QUANTITATIVES}

Note du Secrétariat de l'OMC G/MA/NTM/QR/3 du 25 mars $2004^{45}$

1. La Décision sur les procédures de notification des restrictions quantitatives, adoptée par le Conseil du commerce des marchandises (G/L/59), dispose que «les Membres présenteront des notifications complètes des restrictions quantitatives qu'ils appliquent, d'abord pour le 31 janvier 1996, puis à intervalles de deux $a^{46}{ }^{46}$, et ils notifieront les changements apportés à leurs restrictions quantitatives lorsque ces changements interviendront $»$. Les Membres qui ont présenté, au titre d'autres dispositions d'instruments de l'OMC, des notifications de restrictions quantitatives qui répondent aux prescriptions établies pour les notifications de restrictions quantitatives aux termes des Décisions de 1984 et 1985 et qui sont à jour, notifieront ce fait au Secrétariat. Ces notifications seront stockées dans la nouvelle base de données sur les restrictions quantitatives.

2. Le présent document a été établi par le Secrétariat conformément à la décision susmentionnée, selon laquelle «le Secrétariat publiera périodiquement un document contenant la liste des Membres de l'OMC qui ont présenté une notification ». On trouvera ci-après cette liste, dans laquelle figure l'année où les notifications ont été faites.

3. Depuis 1996, les Membres ci-après ont notifié des restrictions quantitatives: Afrique du Sud (1996); Allemagne-Communautés européennes (2000); Argentine (1997); Australie (1996); Bahreïn, Royaume de (1997, 2000); Bulgarie (2003); Chili (1996); Chine (2002, 2003); Chypre (1996); Communautés européennes (1996, 1998, 2000, 2002); Corée, Rép. de (1997); États-Unis d'Amérique (1999); Fidji (1997); Géorgie (2003); Hong Kong, Chine (1996, 1998, 2000, 2002); Hongrie (1996, 1998, 2000, 2002); Inde (1996, 1997, 1998); Jamaïque (1996, 1998, 2002); Japon (1998, 2000, 2002); Liechtenstein (1997, 2002); Macao, Chine (1996, 1999, 2001, 2003); Maldives (1999); Malte (1996, 2000); Maroc (1997, 1999, 2001, 2002); Nigeria (2002); Norvège (1996, 2000); Nouvelle-Zélande (1996); Oman (2001, 2004); Pakistan (1997); Pérou (1996, 1997); Philippines (1996); Suisse (1997, 2001); Taipei chinois (2002); Tunisie $(1999,2001)$; Turquie $(1996,1998$, 2000); Venezuela (1996, 1999); Zambie (1996, 2002).

4. Les Membres ci-après ont notifié des changements apportés à leurs restrictions quantitatives: Argentine (2002); Bahreïn, Royaume de (2000); Chine (2003); Communautés européennes (1998, 2000); Hong Kong, Chine (1996); Inde (1996, 1998); Jamaïque (2002); Macao, Chine (2001, 2004); Maldives (1999); Malte (2000); Maroc (1999, 2002); Norvège (2000); Pérou (1997); Tunisie (2001); Turquie (1998, 2000); Zambie (1997).

5. Les Membres ci-après ont notifié qu'ils n'appliquaient pas de restrictions quantitatives: Argentine (2002); Bolivie (1997); Brunei Darussalam (1996); Burundi (2001); Costa Rica (1998); Dominique (2001); Émirats arabes unis (1996, 1997, 2000); Estonie (2002); Gabon (2001); Gambie (1997); Guatemala (1999, 2000); Guyana (2003); Haïti (1999); Honduras (1997); Islande (1996, 2000); Jordanie (2002); Lettonie (1999); Madagascar (2001); Moldova (2002); Mongolie (2000); Myanmar (2001); Namibie (1999); Ouganda (1996, 2000); Paraguay (1998); Qatar (1999);

\footnotetext{
${ }^{45}$ Le présent document a été établi par le Secrétariat sous sa propre responsabilité et sans préjudice des positions des Membres ni de leurs droits et obligations dans le cadre de l'OMC.

${ }^{46}$ Pour le 31 janvier 1998, pour le 31 janvier 2000, pour le 31 janvier 2002, pour le 31 janvier 2004.
} 
République dominicaine (1996); République kirghize (2000); Singapour (1996); Sri Lanka (2003); Trinité-et-Tobago (1998); Uruguay (1996, 1999); Zambie (2002); Zimbabwe (2000, 2003). 
ANNEXE 2.

Mesures d'interdiction et de contingentement des importations associées à l'environnement notifiées à l'OMC en 2000 et 2001. Sources : WT/CTE/W/195; WT/CTE/EDB/1.

1. Mesures notifiées au titre de l'Accord sur les restrictions quantitatives

\begin{tabular}{|c|c|c|}
\hline Membre & Mesure ou produit & Objectif \\
\hline \multirow[t]{2}{*}{ Macao (Chine) } & $\begin{array}{l}\text { Les véhicules automobiles, autres véhicules à } \\
\text { moteur, tracteurs et cyclomoteurs d'occasion, } \\
\text { leurs parties et accessoires sont soumis à des } \\
\text { prohibitions }\end{array}$ & Protéger l'environnement (entre autres) \\
\hline & $\begin{array}{l}\text { Les CFC, halons, et autres hydrocarbures } \\
\text { halogénés, tétrachlorure de carbone, } \\
\text { trichloroéthane et bromométhane font l'objet d'un } \\
\text { contingent global. }\end{array}$ & $\begin{array}{l}\text { Exécution des obligations découlant du Protocole } \\
\text { de Montréal }\end{array}$ \\
\hline \multirow[t]{2}{*}{ Bahreïn } & Interdictions concernant le "Bulbul" pakistanais & Préserver l'environnement local et les oiseaux \\
\hline & Interdictions concernant l'ivoire ouvré & Préserver l'environnement \\
\hline \multirow[t]{3}{*}{$\begin{array}{l}\text { Hong Kong } \\
\text { (Chine) })^{47}\end{array}$} & $\begin{array}{l}\text { Interdictions concernant les espèces en voie } \\
\text { d'extinction d'animaux et de plantes inscrites à } \\
\text { l'Annexe I de la CITES }\end{array}$ & Satisfaire aux obligations découlant de la CITES \\
\hline & $\begin{array}{l}\text { Interdictions concernant les chlorofluorocarbones, } \\
\text { isolés ou en combinaison }\end{array}$ & $\begin{array}{l}\text { Satisfaire aux obligations découlant du Protocole de } \\
\text { Montréal }\end{array}$ \\
\hline & $\begin{array}{l}\text { Contingents mondiaux et licences non automatiques } \\
\text { concernant les HCFS et les dérivés halogénés des } \\
\text { hydrocarbures acycliques contenant au moins deux } \\
\text { halogènes différents }\end{array}$ & $\begin{array}{l}\text { Satisfaire aux obligations découlant du Protocole de } \\
\text { Montréal }\end{array}$ \\
\hline \multirow[t]{3}{*}{ Japon } & $\begin{array}{l}\text { Contingents d'importation d'animaux et de plantes et } \\
\text { de produits issus de ces animaux ou de ces plantes } \\
\text { visés par la CITES, et substances réglementées } \\
\text { énumérées dans le Protocole de Montréal }\end{array}$ & $\begin{array}{l}\text { Satisfaire aux obligations découlant de la CITES et du } \\
\text { Protocole de Montréal }\end{array}$ \\
\hline & $\begin{array}{l}\text { Les véhicules automobiles, autres véhicules à } \\
\text { moteur, tracteurs et cyclomoteurs d'occasion, } \\
\text { leurs parties et accessoires sont soumis à des } \\
\text { prohibitions }\end{array}$ & Protéger l'environnement (entre autres) \\
\hline & $\begin{array}{l}\text { Les CFC, halons, et autres hydrocarbures } \\
\text { halogénés, tétrachlorure de carbone, } \\
\text { trichloroéthane et bromométhane font l'objet d'un } \\
\text { contingent global }\end{array}$ & $\begin{array}{l}\text { Satisfaire aux obligations découlant du Protocole de } \\
\text { Montréal }\end{array}$ \\
\hline
\end{tabular}

${ }^{47}$ Cette notification est également présentée au titre de l'Accord sur les procédures de licences d'importation (G/LIC/N/3/HKG/4). 
TD/TC/WP(2004)28/FINAL

2. Mesures notifiées au titre de l'Accord sur les obstacles techniques au commerce

\begin{tabular}{|l|l|l|}
\hline Chili & $\begin{array}{l}\text { Interdiction de mélanger du kérosène avec } \\
\text { d'autres combustibles et établissement de } \\
\text { prescriptions applicables au kérosène destiné à } \\
\text { des usages domestique et industriel stocké, } \\
\text { distribué et commercialisé. }\end{array}$ & $\begin{array}{l}\text { Maîtriser l'augmentation de la pollution } \\
\text { atmosphérique }\end{array}$ \\
\hline Pays-Bas & $\begin{array}{l}\text { Règlement interdisant la fabrication de la } \\
\text { substance 1,1'-(isopropylidène)bis[3,5- } \\
\text { dibrome-4-(2,3-dibrome propoxy)benzène], } \\
\text { qu'elle soit ou non transformée et utilisée dans } \\
\text { une préparation ou un produit, son importation }\end{array}$ & Protection de l'environnement \\
& $\begin{array}{l}\text { aux Pays-Bas, son utilisation ou sa } \\
\text { disponibilité dans les stocks de commerce }\end{array}$ & \\
\cline { 2 - 3 } & $\begin{array}{l}\text { Décret concernant des exemptions des interdictions } \\
\text { de commerce de la préparation de certaines espèces }\end{array}$ & $\begin{array}{l}\text { Prévenir la capture de gibier en vue de la préparation } \\
\text { illicite des animaux }\end{array}$ \\
\hline États-Unis & $\begin{array}{l}\text { Restrictions ou interdictions d'utilisation de } \\
\text { produits de remplacement des substances } \\
\text { appauvrissant la couche d'ozone dans le cadre du } \\
\text { Programme pour de nouvelles solutions de } \\
\text { substitution de l'Agence de protection de } \\
\text { l'environnement }\end{array}$ & $\begin{array}{l}\text { Activer l'abandon des substances détruisant l'ozone } \\
\text { tout en évitant la substitution de produits qui posent } \\
\text { d'autres problèmes de protection de l'environnement }\end{array}$ \\
\hline
\end{tabular}


ANNEXE 3.

Informations sur les restrictions quantitatives (interdictions, contingents et commerce d'État) de la base de données d'accès au marché de l'Union européenne, disponible sur le site http://mkaccdb.eu.int

\begin{tabular}{|c|c|c|}
\hline Pays & $\begin{array}{l}\begin{array}{l}\text { Secteur/ type de } \\
\text { produit }\end{array} \\
\text {. }\end{array}$ & Caractéristiques \\
\hline $\begin{array}{l}\text { Bangladesh } \\
(2003)\end{array}$ & Textiles et cuir & $\begin{array}{l}\text { Le Bangladesh applique une restriction à l'exportation de peaux brutes et de } \\
\text { cuir à l'état bleu humide en vertu de sa politique d'exportation (1997-2002). } \\
\text { Seules les exportations de produits en cuir fini et en cuir sont autorisés. } \\
\text { Selon les autorités bangladaises, cette interdiction a pour objet de maintenir } \\
\text { une offre nationale suffisante et de favoriser le développement de l'industrie } \\
\text { nationale du cuir. Cette interdiction semble toutefois constituer une violation } \\
\text { manifeste de l'article XI du GATT. }\end{array}$ \\
\hline $\begin{array}{l}\text { Brésil } \\
(2003)\end{array}$ & $\begin{array}{l}\text { Marchandises et } \\
\text { pneus usagés }\end{array}$ & $\begin{array}{l}\text { En } 2000 \text {, le Brésil a élargi l'interdiction générale d'importation de pneus } \\
\text { usagés aux pneus rechapés ou recyclés. D'après les autorités brésiliennes, } \\
\text { cette interdiction a été introduite pour des raisons environnementales. Or, cet } \\
\text { argument ne semble pas valable puisque les pneus rechapés, en tant que } \\
\text { produits nouveaux, n'entrent pas dans la définition des déchets de la } \\
\text { Convention de Bâle, ni dans celle du Règlement de la Communauté } \\
\text { européenne sur le transferts de déchets non dangereux vers les pays non } \\
\text { membres de l'OCDE. En outre, l'interdiction cré une distinction } \\
\text { discriminatoire entre les produits brésiliens et les produits importés du fait } \\
\text { qu'il existe au Brésil une industrie nationale de pneus rechapés, dont la } \\
\text { commercialisation est légitime. }\end{array}$ \\
\hline $\begin{array}{l}\text { Brésil } \\
(2003)\end{array}$ & $\begin{array}{l}\text { Véhicules } \\
\text { d'occasion }\end{array}$ & L'importation d'automobiles et de motocyclettes d'occasion est interdite. \\
\hline $\begin{array}{l}\text { Canada } \\
(2001)\end{array}$ & $\begin{array}{l}\text { Véhicules } \\
\text { d'occasion }\end{array}$ & $\begin{array}{l}\text { Aux termes du Tarif des douanes canadien (numéro tarifaire } 9897.00 .00 \text {, } \\
\text { Mémorandum D9-1-11) une interdiction sur l'importation de véhicules } \\
\text { automobiles de toutes sortes, usagés ou d'occasion reste en vigueur, sauf en } \\
\text { ce qui concerne les véhicules importés des États-unis; l'importation de } \\
\text { véhicules d'occasion du Mexique doit être progressivement libéralisée ; ils } \\
\text { devraient bénéficier d'un accès illimité en } 2019 \text {. }\end{array}$ \\
\hline $\begin{array}{l}\text { Canada } \\
(2002)\end{array}$ & Textiles & $\begin{array}{l}\text { Le Canada maintient des contingents sur certains textiles et produits } \\
\text { d'habillement }\end{array}$ \\
\hline $\begin{array}{l}\text { Chine } \\
(2002)\end{array}$ & $\begin{array}{l}\text { Produits } \\
\text { électroniques }\end{array}$ & $\begin{array}{l}\text { Aux termes de l'accord d'accession de la Chine à l'OMC, les contingents } \\
\text { d'importation portant sur certains produits électroniques (téléviseurs } \\
\text { couleur, calculatrices électroniques, récepteurs de télévision individuels par } \\
\text { satellite, imprimantes, radiocassettes, radios-réveils, lecteurs de disques } \\
\text { laser, caméras enregistreuses vidéo) devraient être progressivement éliminés } \\
\text { d'ici à 2004, conformément aux prévisions. }\end{array}$ \\
\hline $\begin{array}{l}\text { Chine } \\
(2002)\end{array}$ & Textiles & $\begin{array}{l}\text { La Chine applique des contingents d'importation aux textiles. En vertu des } \\
\text { engagements qu'elle a contractés pour adhérer à l'OMC, elle devrait } \\
\text { commencer à supprimer ces continents lors de son accession à } \\
\text { l'Organisation. }\end{array}$ \\
\hline
\end{tabular}




\begin{tabular}{|c|c|c|}
\hline $\begin{array}{l}\text { Chine } \\
(2002)\end{array}$ & Automobiles & $\begin{array}{l}\text { Jusqu'à son accession à l'OMC, la Chine soumettait les importations } \\
\text { d'automobiles à des contingents et à un régime de licences d'importation. En } \\
\text { vertu des obligations contractées à l'occasion de son accession à l'OMC, elle } \\
\text { devrait éliminer progressivement ces contingents à l'horizon 2005. Le } \\
\text { montant initial des contingents devrait s'élever à USD } 6 \text { milliards en } 2001 \text {, } \\
\text { avec une première augmentation de } 15 \% \text {. La première année, } 25 \% \text { du } \\
\text { contingent sera alloué à de nouveaux importateurs (à savoir } \\
\text { USD 1,5 milliard). }\end{array}$ \\
\hline $\begin{array}{l}\text { Chine } \\
(2003)\end{array}$ & Cosmétiques & $\begin{array}{l}\text { La Chine a publié en mars } 2002 \text { un nouveau règlement qui interdit } \\
\text { l'importation de produits cosmétiques contenant certains ingrédients } \\
\text { d'origine animale de } 18 \text { pays ayant officiellement déclaré des cas d'ESB. La } \\
\text { justification invoquée à cette mesure est la protection de la santé humaine. }\end{array}$ \\
\hline $\begin{array}{l}\text { Égypte } \\
(2002)\end{array}$ & $\begin{array}{l}\text { Véhicules } \\
\text { d'occasion }\end{array}$ & $\begin{array}{l}\text { L'importation d'automobiles particulières a été assujettie à de rigoureuses } \\
\text { restrictions en } 1999 \text {. De nouvelles mesures limitent les importations aux } \\
\text { véhicules fabriqués l'année où ils sont importés. }\end{array}$ \\
\hline $\begin{array}{l}\text { Égypte } \\
(2002)\end{array}$ & Textiles & $\begin{array}{l}\text { Le } 1^{\text {er }} \text { janvier 1998, l'Égypte a levé l'interdiction qui pesait sur les } \\
\text { importations de tissus dans le secteur textile, mais a introduit le même jour } \\
\text { des règles d'étiquetage extrêmement lourdes. }\end{array}$ \\
\hline $\begin{array}{l}\text { Inde } \\
(2002)\end{array}$ & Général & $\begin{array}{l}\text { L'Inde applique différentes sortes de restrictions aux importations (licences } \\
\text { non automatiques, produits interdits et produits ne pouvant être importés que } \\
\text { par les monopoles de commerce d'État par exemple). La plupart revêtent la } \\
\text { forme de licences non automatiques. La liste des restrictions de } 2001 \\
\text { comptait environ } 582 \text { articles et portait sur des produits agricoles, des } \\
\text { produits chimiques, des fertilisants, des produits pharmaceutiques, le métal, } \\
\text { les pierres, les bijoux, les appareils de transmission, les hélicoptères et les } \\
\text { avions, pour n'en citer que quelques-uns. Souvent, le régime de licences non } \\
\text { automatiques a pour effet d'interdire ou de prévenir l'entrée sur le marché } \\
\text { national d'importations qui font concurrence à certains produits au plan } \\
\text { commercial. } \\
\text { La politique d'import-export pour } 2002-2007 \text { instaurée en mars } 2002 \\
\text { marquait une certaine évolution en ce qu'elle supprimait } 63 \text { articles de la } \\
\text { liste des restrictions. Les principaux produits dont l'interdiction a été levée } \\
\text { appartiennent aux catégories des produits pharmaceutiques, des } \\
\text { antibiotiques, des produits chimiques (sous certaines conditions), des } \\
\text { composés organiques et inorganiques, des pierres précieuses et des bijoux. } \\
\text { Certains insecticides et pesticides (32 produits de la catégorie } 3808 \text { ont été } \\
\text { libérés à condition d'être enregistrés et de ne pas être interdits à } \\
\text { l'importation en vertu de la loi sur les insecticides. }\end{array}$ \\
\hline $\begin{array}{l}\text { Japon } \\
(2003)\end{array}$ & $\begin{array}{l}\text { Phtalate dans les } \\
\text { jouets et les } \\
\text { emballages aptes au } \\
\text { contact alimentaire }\end{array}$ & $\begin{array}{l}\text { En octobre 2001, les autorités japonaises ont notifié à l'OMC leur intention } \\
\text { de limiter l'usage de deux plastifiants, le phtalate de diisononyle (DINP) et } \\
\text { les exportations de di (2-éthylhexyle) dans certains produits aptes au contact } \\
\text { alimentaire et jouets en résine synthétique. }\end{array}$ \\
\hline $\begin{array}{l}\text { Mexique } \\
\text { (2001) }\end{array}$ & $\begin{array}{l}\text { Véhicules } \\
\text { d'occasion }\end{array}$ & $\begin{array}{l}\text { À l'heure actuelle, le Mexique exige un permis d'importation pour la plupart } \\
\text { des véhicules d'occasion fabriqués aux États-unis, au Canada et dans } \\
\text { l'Union européenne. Les permis ne sont concédés qu'aux véhicules } \\
\text { spécialisés dont la production n'est pas significative au Mexique, comme les } \\
\text { ambulances et les véhicules adaptés aux personnes handicapées. Dans la } \\
\text { pratique, les importations de véhicules d'occasion sont interdites. } \\
\text { L'accord de libre échange UE-Mexique supprime toutes les interdictions ou } \\
\text { restrictions d'importation autres que les droits et taxes douaniers, qu'ils } \\
\text { soient appliqués au travers de contingents, de licences d'importation ou } \\
\text { d'autres mesures (art. 12). Néanmoins, l'annexe IV.6 autorise le Mexique à } \\
\text { maintenir des interdictions ou restrictions d'importation sur quasiment tous } \\
\text { les véhicules d'occasion. }\end{array}$ \\
\hline
\end{tabular}


TD/TC/WP(2004)28/FINAL

\begin{tabular}{|c|c|c|}
\hline $\begin{array}{l}\text { Mexique } \\
(2001)\end{array}$ & Machines usagées & $\begin{array}{l}\text { Des licences d'importation sont requises pour l'importation de certaines } \\
\text { machines usagées. La liste des machines assujetties à un permis } \\
\text { d'importation obligatoire comprend les machines de traitement automatique } \\
\text { des données, les lecteurs magnétiques ou optiques et les transcripteurs de } \\
\text { données sur des médias de données sous forme codée. Dans la pratique, les } \\
\text { importations de machines usagées sont interdites. L'accord de libre échange } \\
\text { entre le Mexique et l'Union européenne autorise le Mexique àmaintenir des } \\
\text { interdictions ou restrictions sur l'importation des produits usagés } \\
\text { susmentionnés jusqu'au } 31 \text { décembre } 2003 \text {. }\end{array}$ \\
\hline $\begin{array}{l}\text { Nigeria } \\
(2002)\end{array}$ & Produits usagés & $\begin{array}{l}\text { Les véhicules vieux de plus de cinq ans à compter de la date de fabrication. } \\
\text { Les réfrigérateurs, les climatiseurs et les compresseurs usagés. }\end{array}$ \\
\hline $\begin{array}{l}\text { Nigeria } \\
(2002)\end{array}$ & Textiles & $\begin{array}{l}\text { Les textiles contenant des produits chimiques dangereux, comme le } \\
\text { chlorure. }\end{array}$ \\
\hline $\begin{array}{l}\text { Nigeria } \\
(2002)\end{array}$ & Produits divers & $\begin{array}{l}\text { Le } 7 \text { janvier 2004, le Federal Executive Council a approuvé la liste suivante } \\
\text { de produits interdits d'importation au Nigeria: *Cartons ondulés et rideaux, } \\
\text { textiles, chaussures pour hommes et sacs (cuir et plastique), savon et } \\
\text { détergents, meubles, bicyclettes (assemblées), fleurs (fraîches et en } \\
\text { plastique), aliments frais, sabres et produits associés, pâte à dentifrice, } \\
\text { crayons et stylos billes, produits en plastique, barytine et bentonite, huile } \\
\text { végétale, produits carnés. }\end{array}$ \\
\hline $\begin{array}{l}\text { Singapour } \\
\text { (2001) }\end{array}$ & Gomme à mâcher & $\begin{array}{l}\text { L'importation de gomme à mâcher est interdite pour des raisons de sécurité } \\
\text { publique. }\end{array}$ \\
\hline $\begin{array}{l}\text { Taiwan } \\
(2003)\end{array}$ & Automobiles & $\begin{array}{l}\text { Taiwan a de tous temps interdit l'importation d'automobiles particulières } \\
\text { équipées de moteurs diesel, de motocyclettes de } 150 \mathrm{cc} \text { ou plus, et de } \\
\text { véhicules équipés de moteurs à deux temps. Ces restrictions seront } \\
\text { maintenues pendant deux ans après l'accession de Taiwan à l'OMC. Les } \\
\text { autorités ont levé les restrictions sur l'importation de motocyclettes de plus } \\
\text { de } 150 \mathrm{cc} \text { le } 1^{\text {er }} \text { juillet } 2002 \text {. Pour des raisons réglementaires ou, peut-être, } \\
\text { commerciales, il y a peu de motocyclettes de plus de } 150 \mathrm{cc} \text { en circulation. }\end{array}$ \\
\hline $\begin{array}{l}\text { Thaïlande } \\
\text { (2001) }\end{array}$ & $\begin{array}{l}\text { Véhicules } \\
\text { automobiles }\end{array}$ & $\begin{array}{l}\text { L'importation d'autobus à } 6 \text { roues, équipés de plus de } 30 \text { sièges, et celle de } \\
\text { motocyclettes, est interdite afin de protéger l'industrie nationale } \\
\text { (embryonnaire). Ces interdictions ont été transformées en licences non } \\
\text { automatiques. Par ailleurs, les importations de produits automobiles usagés } \\
\text { sont interdites pour des motifs de santé publique. Les seules importations } \\
\text { autorisées sont effectuées par des entreprises publiques, ou sont admises à } \\
\text { titre temporaire avant réexportation. }\end{array}$ \\
\hline $\begin{array}{l}\text { États-Unis } \\
(2002)\end{array}$ & $\begin{array}{l}\text { Textiles } \\
\text { vêtements }\end{array}$ & $\begin{array}{l}\text { Des restrictions quantitatives sont en vigueur pour des raisons commerciales } \\
\text { dans quelques secteurs seulement, notamment les textiles et les vêtements.. }\end{array}$ \\
\hline
\end{tabular}




\section{ANNEXE 4.}

Informations sur les prohibitions et contingents dégagées des Examens des politiques commerciales de l'OMC réalisées entre 1998 et 2004.

Australie (2002) Interdictions pour des raisons de santé humaine, d'hygiène et d'assainissement, de protection de la vie animale et végétale, de préservation de l'environnement, de sécurité essentielle, conformément aux obligations législatives et réglementaires nationales (objectifs de recettes compris) et aux engagements internationaux.

\section{Bangladesh (2000)}

Interdictions pour des raisons sociales, religieuses, sanitaires, écologiques, commerciales ou de sécurité.

Principales catégories : (i) produits exigeant un certificat, une autorisation préalable ou le feu vert des autorités compétentes; (ii) produits qui ne peuvent être importés que par des consommateurs industriels enregistrés, notamment les industries de la confection, du bas, et de certains textiles orientées vers l'exportation opérant dans le cadre du régime de l'entrepôt en douane ${ }^{48}$, les industries pharmaceutiques (allopathiques), et les hôtels opérant en devises, dans les limites du droit à importer spécifié dans leurs certificats d'enregistrement des importations (IRC); (iii) les produits relevant du commerce d'État, notamment les armes et munitions, qui ne peuvent être importés que par des entreprises désignées par l'État; et (iv) les produits assujettis à certaines conditions..

\section{Barbade (2002)}

Interdictions visant à garantir la sécurité nationale, à sauvegarder la santé et la moralité des consommateurs, ou à protéger la vie végétale et animale et l'environnement nationaux.

\section{Bolivie (1999)}

La Bolivie n'applique pas d'interdictions aux importations, sauf en ce qui concerne les produits dont les autorités estiment qu'ils portent atteinte à la santé publique, à l'environnement ou à la moralité.

Les produits interdits sont les produits pharmaceutiques et les médicaments non enregistrés dans le pays ; les boissons et produits alimentaires dénaturés ou frelatés ; les animaux atteints de maladie ; les végétaux contenant des parasites et des microbes, ou déclarés nuisibles par le Ministère de l'agriculture ; les billets de loterie étrangers ; la corde et la ficelle usagées ; les matériaux toxiques et radioactifs ; les publicités imitant des certificats monétaires ou bancaires et les timbres postaux.

L'importation de véhicules d'occasion à conduite à droite transformés en véhicules à conduite à gauche est interdite. Le matériel de réfrigération et de climatisation contenant du CFC-12 est interdit.

\section{Botswana (2003)}

Interdictions visant à protéger la santé, la sécurité et la moralité.

L'importation de produits dangereux pour l'environnement, comme les déchets toxiques ou radioactifs, est interdite. 
Brésil (2000)

Interdictions visant à sauvegarder la santé et le bien-être du consommateur, ou à protéger la vie végétale et animale et l'environnement nationaux.

En mai 2000, aucune importation ne semblait assujettie à des contingents.

Les marchandises importées dans la zone de libre échange de Manaus ont été soumises à des contingents jusqu'en 1998. Ceux portant sur les produits automobiles ont été supprimés le 31 décembre 1999. Certains s'appliquaient également au caoutchouc. L'importation de machines, d'automobiles, de vêtements et de beaucoup d'autres biens de consommation usagés est interdite..

\section{Brunei (2001)}

Les interdictions d'importation sont maintenues sur un petit nombre de produits, notamment l'opium, les pétards, les vaccins en provenance de Taipei chinoise, les armes et munitions, pour des raisons sanitaires, morales et de sécurité.

Par ailleurs, l'importation et la fabrication d'alcool et de produits alcoolisés sont restreintes pour des raisons religieuses en vertu du Customs Prohibitions and Restriction of Imports and Exports Amended Order de 1990. Ce décret, entré en vigueur le $1^{\text {er }}$ décembre 1990, autorise les importations dans le cadre d'une licence émise par le Contrôleur.

Une interdiction d'importation «temporaire » semble s'appliquer au ciment, une interdiction de même nature sur les matériaux de couverture ayant pour sa part été récemment levée.

L'importation de véhicules automobiles d'occasion de plus de cinq ans est interdite dans l'objectif d'améliorer la sécurité routière.

\section{Burundi (2003)}

De 1993 à 2000, le Burundi a progressivement élargi sa liste négative d'importations interdites ou réglementées, en invoquant la pénurie de devises pour justifier cette mesure. Pour remédier à ce problème, un régime de licences a été appliqué jusqu'en août 2002. Depuis la mise en place du processus de paix, les interdictions ont été progressivement levées. Elles s'appliquent actuellement à des produits tels que les stupéfiants, l'ivoire, les armes et les munitions.

\section{Cameroun (2001)}

Interdictions pour des raisons relatives à la sécurité, à l'ordre public, à la santé, à l'environnement et pour des raisons d'urgence.

Canada (2003, 2000)

Interdictions visant à garantir la sécurité nationale, à sauvegarder la santé et la moralité du consommateur, à mettre en ouvre les accords intergouvernementaux, ou à protéger la vie végétale et animale et l'environnement nationaux.

L'importation de réimpressions d'ouvrages canadiens et britanniques protégés par le droit d'auteur au Canada est interdite.

Depuis les années 60, les droits sur les textiles et les vêtements ont été complétés par des contingents d'importation; ces derniers sont progressivement éliminés sur une période de dix ans allant jusqu'à janvier 2005 en vertu de l'Accord sur les textiles et les vêtements de l'OMC. À la fin de 2002, la moitié environ de la valeur des importations de vêtements est entrée au sur le marché canadien sous contingents. Interdiction d'importation sur les véhicules automobiles d'occasion de moins de 15 ans, sauf s'ils sont fabriqués aux États-Unis, et d'avions usagés ou d'occasion, sauf s'ils sont importés des États-Unis. 
Chili (2004)

Interdictions pour des raisons de protection de la santé humaine, de la vie animale et végétale et de l'environnement, conformément à la loi nationale ou aux engagements internationaux.

Interdiction d'importation de véhicules usagés, pour des raisons environnementales selon les autorités. Interdiction d'importation de déchets dangereux (Convention de Bâle) et de produits contenant des CFC (Protocole de Montréal).

\section{Costa Rica (2001)}

Produits interdits : produits qui appauvrissent la couche d'ozone, amiante, armes et explosifs, produits naturels sous forme pharmaceutique et tisanes, produits narcotiques, substances psychotropes et drogues interdites, cosmétiques, produits dangereux et médicaments.

\section{République dominicaine (2002)}

Interdictions pour des raisons de protection de la santé humaine, de la vie animale et végétale, de l'environnement, des intérêts essentiels à la sécurité et des raisons militaires, conformément à la loi nationale ou aux engagements internationaux.

Afin de protéger l'environnement, la loi nationale interdit l'importation de véhicules de plus de cinq ans et de motocyclettes dans les cinq ans suivant leur fabrication, d'appareils électroménagers usagés et de véhicules de plus de cinq tonnes dans les 15 ans suivant leur fabrication, et de vêtements usagés.

\section{Égypte (1999)}

L'Égypte a cessé d'invoquer l'article XVIII:B du GATT (sur les mesures commerciales prises pour des raisons de balance des paiements) le 30 juin 1995, et s'est engagée à supprimer les interdictions d'importation conditionnelles encore en vigueur sur les tissus avant le $1^{\mathrm{er}}$ janvier 1998 , et sur les vêtements et les articles textiles façonnés avant le $1^{\mathrm{e}}$ janvier 2002. Les interdictions conditionnelles sur l'importation de tissus ont été levées en 1998 et remplacées par un droit de douane de $54 \%$. Les mesures non tarifaires sur tous les produits textiles et d'habillement devraient être supprimées d'ici à 2002, conformément aux engagements de l'Égypte au titre du Cycle d'Uruguay. Les importations de marchandises d'occasion sont autorisées pour certains produits quoique, dans la plupart des cas, une autorisation des ministères compétents soit requise.

L'importation de climatiseurs, de réfrigérateurs et de produits aérosols employant des substances nocives pour la couche d'ozone est interdite dans le cadre de la participation de l'Égypte au Protocole de Montréal relatif à des substances qui appauvrissent la couche d'ozone.

\section{El Salvador (2003)}

Prohibition sur l'importation de véhicules particuliers et de transport légers en service depuis plus de huit ans et de véhicules particuliers et de transport lourds en service depuis plus de 15 ans.

\section{Communauté européenne (2002, 2000, 1997)}

Une exigence générale de sécurité s'applique à la mise sur le marché de produits consommables dans les pays de la Communauté, sauf en ce qui concerne ceux pour lesquels des règlements ou des normes spécifiques ont été établis à l'échelon de la Communauté ou des États membres, comme les produits alimentaires. Les États membres peuvent invoquer cette exigence pour prendre des mesures dans des cas d'urgence, et des mesures peuvent être adoptées au niveau communautaire, à l'initiative de la Commission, dans le cadre du système RAPEX pour les produits non alimentaires. En 2000, la Commission a décidé d'interdire la mise sur le marché de jouets et d'articles de puériculture destinés a être mis en bouche par des enfants de moins de trois ans, fabriqués en PVC souple contenant certains phtalates. Cette décision a été constamment prorogée au cours de la période examinée, la dernière fois le 20 février 2002. S' agissant des produits alimentaires, l'UE a adopté en février 2002 un nouvel instrument afin d'assurer la sécurité des aliments. Celui-ci a été utilisé pour la première fois le 27 mars 2002, pour 
suspendre l'importation et la mise sur le marché communautaire de confiseries gélifiées contenant l'additif alimentaire E 425 (konjac).

L'utilisation et la mise sur le marché communautaire de substances dangereuses, par voie d'importation notamment, est rigoureusement réglementée afin de protéger le public; la liste des substances concernées est régulièrement actualisée de manière à tenir compte des progrès techniques. Des interdictions portant sur la créosote et l'hexachloroéthane ont été annoncées, et doivent entrer en vigueur le 30 juin 2003. L'interdiction sur les autres utilisations de l'amiante chrysiotile, qui doit entrer en application d'ici à 2005, a été contestée, sans succès, par le Canada dans le cadre des procédures de règlement des différends de l'OMC.

L'UE contrôle, au travers d'un système commun de notification et d'information pour les importations en provenance des pays tiers et les exportations à destination de ceux-ci, le commerce de certains produits chimiques interdits ou strictement réglementés en raison de leurs effets sur la santé de l'homme et sur l'environnement; la Communauté applique la procédure de consentement préalable en connaissance de cause (procédure PIC) établie par le Programme des Nations Unies pour l'environnement (PNUE) et ll'Organisation des Nations Unies pour l'alimentation et l'agriculture (FAO).

L'UE applique des réglementations au commerce dans le cadre des AEM suivants: Convention sur le commerce international des espèces de faune et de flore sauvages menacées d'extinction (CITES), Convention internationale pour la conservation des thonidés de l'Atlantique (ICCAT), Convention de Bâle et Protocole de Montréal.

Au 1er janvier 2002, l'UE continue d'appliquer dans le cadre de l'OMC des contingents hérités de l'ancien Arrangement multifibres (AMF) sur les importations en provenance d'Argentine, du Brésil, de Hong Kong (Chine), d'Inde, d'Indonésie, de la République de Corée, de Macao, de Malaisie, du Pakistan, du Pérou, des Philippines, de Singapour, du Sri Lanka (suspendus) et de Thaïlande.

En ce qui concerne la Chine, l'UE maintient des contingents hérités de l'AMF dans le cadre de l'Accord sur les textiles et les vêtements, ainsi que d'autres contingents (lin, soie et ramie). S'agissant des premiers, le calendrier qui prévoit la suppression des contingents avant le $1^{\text {er }}$ janvier 2005 est censé s'appliquer. L'UE fixe également des contingents sur les importations en provenance du Belarus, de l'Ouzbékistan et du Vietnam en vertu d'accords bilatéraux. Elle applique des restrictions quantitatives, sur une base autonome, aux importations de la République fédérale de Yougoslavie (Serbie-et-Monténégro) et de la République populaire démocratique de Corée.

Des contingents s'appliquent aux importations de chaussures, d'articles de table et de cuisine (céramiques, porcelaines) en provenance de Chine, et une surveillance est exercée sur certains produits. Lors de l'accession de la Chine à l'OMC, l'UE a pris l'engagement de libéraliser progressivement les contingents et de les supprimer à l'horizon 2005.

L'UE maintient des contingents sur certains produits sidérurgiques importés du Kazakhstan, de la Fédération de Russie et d'Ukraine, et exerce une surveillance sur les importations de certains produits sidérurgiques de même origine.

Gabon (2001)

Mesures de contrôle appliquées aux pesticides et aux produits chimiques industriels conformément au dispositif PIC (principe de consentement préalable en connaissance de cause) du Programme des Nations Unies pour l'environnement (PNUE) et de l'Organisation des Nations Unies pour l'alimentation et l'agriculture (FAO).

\section{Gambie (2004)}

L'importation des produits suivants est prohibée: pièces de monnaie ou billets de banque contrefaits ou non conformes, articles portant atteinte aux bonnes mœurs et matériel pornographique, armes à feu non dotées du permis approprié, stupéfiants, menottes, diamants bruts ou non taillés, certains types de gaz délétères, et livres, journaux ou tout autre support de quelque nature que ce soit qui constituent des ouvrages séditieux, scandaleux ou portant atteinte à la morale. 
L'adhésion de la Gambie à la CITES l'a conduite à prohiber les importations d'ivoire et d'ouvrages en ivoire, de peaux d'animaux sauvages y compris les peaux de serpents et les articles fabriqués avec celles-ci, ainsi que les importations de coquilles et de carapaces..

\section{Ghana (2001)}

Interdictions afin de protéger la santé humaine et la sécurité nationale, par exemple des restrictions sur l'importation d'articles obscènes, d'armes dangereuses, d'aliments contaminés ou de carcasses animales infectées.

L'importation de véhicules automobiles, dont les camions, camionnettes et autobus de plus de dix ans, a été interdite en 2000. Auparavant, les véhicules importés ayant dépassé l'âge limite étaient assujetti à une pénalité tarifaire.

\section{Guatemala (2002)}

Interdictions pour la protection de la santé humaine, de la vie animale et végétale, de l'environnement, ou des intérêts essentiels à la sécurité et des raisons militaires, conformément à la loi nationale ou aux engagements internationaux. Le Guatemala applique les interdictions d'importation de manière égale à tous ses partenaires commerciaux.

Les déchets humains ou animaux, traités ou non traités, sont interdits. Les produits contenant des produits CFC qui ne sont pas commercialisés librement et légalement dans leur pays d'origine sont prohibés.

\section{Guyana (2003)}

Interdictions sur l'importation de pièces de monnaie contrefaites ou non conformes, sur les aliments impropres à la consommation, les articles portant atteinte aux bonnes mœurs et les allumettes contenant du phosphore blanc et jaune.

\section{Haïti (2003)}

Interdictions pour des motifs de santé, de sécurité ou de moralité. La liste des produits comprend les brochures, les imprimés ou les films de nature pornographique ; les chars et les véhicules blindés et leurs pièces détachées, les bateaux, armes et munitions non destinés au gouvernement, les stupéfiants, et les équipements destinés à la fabrication ou à l'impression de devises ou de titres contrefaits.

Haïti n'est pas partie à la Convention sur le commerce international des espèces de faune et de flore sauvages menacées d'extinction (CITES) mais, selon les autorités, en applique les directives.

\section{Honduras (2003)}

Interdictions pour des motifs de santé, de sécurité, de moralité publique ou de protection de l'environnement. Les produits interdits comprennent les stupéfiants, les narcotiques, les substances psychotropes et les articles pornographiques.

Hong Kong (Chine) (2002)

Interdictions visant à garantir la sécurité, à protéger l'environnement et la santé publique et à respecter les obligations internationales, notamment les résolutions du Conseil de Sécurité des Nations Unies et les conventions internationales telles que la Convention de Bâle, le protocole de Montréal et la CITES. En général, les importations de toutes les substances appauvrissant la couche d'ozone (SAO) sont interdites. Néanmoins, depuis le $1^{\text {er }}$ janvier 1995 et le $1^{\text {er }}$ janvier 1996, respectivement, les importations de bromométhane et de HCFC originaires d'un pays partie au Protocole de Montréal sont autorisées, aux fins de consommation locale uniquement (autrement dit, pas aux fins de réexportation).

Islande (2000)

Interdictions sur les narcotiques et drogues dangereuses, différentes armes, et sur les importations de substances appauvrissant la couche d'ozone autres que l'hydrochlorofluorocarbure (HCFC). 
Inde (2002)

Si la plupart des restrictions appliquées pour des raisons de balance des paiements ont été levées, d'autres sont maintenues sur certains produits pour des raisons de santé, de sécurité et de moralité publique, notamment sur les armes à feu, les explosifs et les munitions, certains médicaments et drogues, et les bijoux. Elles ont été notifiées par l'Inde en vertu des articles XX et XXI du, GATT de 1947. L'âge des véhicules automobiles d'occasion importés ne doit pas dépasser trois ans à compter de la date de fabrication. Ils doivent en outre satisfaire à plusieurs impératifs techniques. Les autorités soutiennent que les restrictions sont maintenues aux fins de protection du consommateur et de sécurité routière. Par ailleurs, les interdictions pesant sur les déchets, les rognures et les débris de matières plastiques, ont été allégées en autorisant l'importation de ces produits par les zones franches industrielles.

L'importation de produits protégés en vertu de la loi sur la protection de la faune de 1972, de la Convention sur le commerce international des espèces de faune et de flore sauvages menacées d'extinction (CITES), et du Protocole de Montréal relatif à des substances qui appauvrissent la couche d'ozone est également interdite.

\section{Indonésie (2003)}

Interdictions pour des raisons de moralité publique, d'ordre public, de sécurité publique ; pour protéger la santé ou la vie humaines ou animales, les végétaux, l'environnement, les trésors nationaux de valeur artistique, historique ou archéologique, la propriété industrielle ou commerciale, les consommateurs ; aux motifs d'emballage des produits, d'inspections douanières ou de contrôle des opérations financières avec d'autres pays. L'importation d'automobiles de luxe est interdite (depuis le $1^{\text {er }}$ juin 2000).

\section{Israël (1999)}

Les interdictions ont trait à des considérations de moralité publique, de santé ou de sécurité.

Japon $(2002,2000)$

Les interdictions s'appliquent à cinq catégories de produits : narcotiques ; revolvers et pistolets ; imitations de devises; livres et autres articles estimés contraires à la sécurité publique ou à la moralité ; et articles contrevenant aux brevets ou à d'autres droits de propriété intellectuelle.

Certains produits, dont le poisson, les fils de soie et certains tissus de soie, sont assujettis à des contingents d'importation ou à des restrictions aux termes d'accords et arrangements commerciaux bilatéraux, par exemple avec la Chine et la République de Corée.

\section{Kenya (2000)}

Interdictions pour des raisons de moralité, de santé, de sécurité et de protection de l'environnement, et en vertu de conventions internationales.

\section{Corée (2000)}

Interdictions aux fins de protection de la moralité publique, la santé humaine, l'hygiène et l'assainissement, la vie animale et végétale, l'environnement ou des intérêts essentiels de sécurité, conformément aux prescriptions de la loi nationale ou aux engagements internationaux.

La loi n 218 du 22 mai 1984 interdit l'importation de déchets humains, animaux et industriels.

\section{Madagascar (2001)}

Interdictions pour des raisons de santé, de sécurité ou de moralité ; elles portent sur des produits tels que les armes, les explosifs et les produits radioactifs. Des restrictions s'appliquent aussi à l'importation de produits que les autorités jugent stratégiques (vanilline et pierres précieuses). 
Malaisie (2001)

Interdictions pour des motifs de moralité et de sécurité nationale. Pas de modification notable à la liste des produits interdits depuis le dernier EPC. Les produits interdits sont les articles portant impression ou reproduction de tout billet de monnaie, de billet bancaire ou d'emblèmes et dispositifs dont il serait raisonnable de supposer qu'ils seront utilisés de manière préjudiciable ou contraire à la paix, au bien-être ou à l'ordre public en Malaisie ; les articles indécents ou obscènes; les tissus portant impression ou reproduction de versets du Coran; les épées et couteaux à lame rentrante; certains récepteurs de radiodiffusion ; certaines liqueurs contenant du plomb ; l'arsénite de sodium ; tous les genres de poissons piranha; les oufs de tortue; les cabosses de cacao, les ramboutans, les kapoulasans, les longani et les fruits namam produits dans les Philippines et en Indonésie; les crayons, stylos billes et autres articles ressemblant à des seringues; et certains produits chimiques nocifs.

\section{Maldives (2003)}

Interdictions pour des motifs de santé, de sécurité, de sûreté, et pour des raisons environnementales et religieuses. Les produits interdits comprennent les armes et munitions; l'alcool et les boissons spiritueuses ; le porc et ses produits dérivés ; les chiens ; les animaux dangereux ; les documents offensant pour l'Islam, les idoles religieuses, le matériel pornographique, les narcotiques et les porcs vivants.

Les importations de véhicules automobiles et de motocyclettes usagés de plus de cinq ans et trois ans respectivement sont interdites pour des raisons environnementales.

\section{Mauritanie (2002)}

Interdictions pour des motifs de sécurité, d'ordre public et de santé. Produits interdits : alcool (sans autorisation des autorités); armes et munitions; or et diamants bruts ; matériel militaire ; matériel de guerre; drogues; explosifs et imitations frauduleuses. Les appareils de distillation, les graines, les diamants bruts, les publications ou films obscènes, la saccharine, les produits narcotiques et les explosifs peuvent être autorisés par un fonctionnaire, un ministère ou une administration publique compétents. Selon les autorités, la Mauritanie n'applique pas actuellement de restrictions quantitatives sur les importations dans le but de protéger la production nationale.

\section{Mexique (2002)}

Des interdictions s'appliquent à 17 positions tarifaires pour des raisons de sécurité publique, de santé, de moralité ou de protection de l'enfance. Les importations interdites sont classées sous les positions tarifaires suivantes : 0301.9901, 1211.9002, 1302.1102, 1302.1902, 2833.2903, 2903.5903, 2903.5905, 2910.9001, 2925.1901, 2931.0005, 2939.1002, 3003.4001, 3003.4002, 3004.4001, 3004.4002, 4908.9005, 4911.9105. Le Mexique impose également des interdictions d'importation à un certain nombre de pays, conformément aux résolutions du Conseil de sécurité des Nations Unies.

\section{Maroc (2003)}

Des interdictions ou restrictions d'importation peuvent être imposées en vertu d'une loi spéciale sur les produits suivants : produits narcotiques et substances psychotropes; armes, pièces d'armes, et munitions, à l'exception de celles destinées à l'armée; documents écrits ou imprimés, dessins, affiches, gravures, peintures, photographies, diapositives ou reproductions de nature pornographique et tout article contraire à la moralité ou susceptible de troubler l'ordre public.

\section{Mozambique (2001)}

Interdictions pour des motifs de santé, de moralité ou de contrefaçon, qui concernent notamment le matériel pornographique, les produits narcotiques et certaines automobiles usagées de plus de cinq ans. Certains produits ne peuvent être importés qu'à titre temporaire. D'autres produits particuliers sont assujettis à des règles d'importation spéciales et à des licences : certains médicaments, les armes et explosifs, certains vêtements usagés, l'or, l'argent et le platine, certaines monnaies étrangères et nationales. L'importation de certains vêtements et pneus usagés est interdite. 
Namibie (2003)

L'importation de certains produits est interdite par suite de la participation de la Namibie aux accords multilatéraux suivants : Protocole de Montréal relatif à des substances qui appauvrissent la couche d'ozone, Convention de Vienne et amendement de Londres; Convention de Bâle sur le contrôle des mouvements transfrontières de déchets dangereux et de leur élimination et Protocole de Cartagena sur la biosécurité.

\section{Nouvelle-Zélande (2003)}

Plusieurs importations sont interdites ou limitées pour des motifs de santé et de sécurité ou conformément aux conventions internationales auxquelles la Nouvelle-Zélande est partie.

\section{Nicaragua (1999)}

Prohibitions aux fins de protection de la santé humaine, de la vie animale et végétale, de l'environnement ou des intérêts essentiels de sécurité et pour des raisons militaires, conformément à la loi nationale ou aux engagements internationaux.

Depuis 1995, des interdictions ont été décrétées à l'encontre de l'importation de boissons alcoolisées, de pièces détachées, de produits médicamenteux et pharmaceutiques, de peintures, de produits chimiques, d'articles de cuisine, de véhicules Land Rover, et de tissus fabriqués par certaines entreprises. En juillet 1999, 12 prohibitions d'importations à l'encontre d'importations parallèles demeuraient en vigueur.

\section{Norvège (2000)}

Les interdictions pour des raisons de sécurité ou de santé portent sur l'amiante et les produits contenant de l'amiante; les produits contenant des CFC, des halons, du tétrachlorure de carbone, de méthyl chloroforme et autres substances qui appauvrissent la couche d'ozone ${ }^{49}$. Des interdictions d'importation s'appliquent à certains végétaux vivants et à des végétaux hôtes de certaines maladies.

\section{Pakistan (2002)}

Le nombre de produits interdits semble avoir diminué. En septembre 2000, la liste contenait 71 articles (à l'exclusion des produits d'ordre général) classés sous 121 rubriques du SH, contre 75 en 1994 (GATT, 1995). D'autres modifications à la liste négative sont le retrait de plusieurs produits interdits pour des motifs commerciaux (pommes de terre, certains produits textiles et d'habillement).

Les principales interdictions pour des motifs commerciaux qui visaient de nombreux textiles, articles d'habillement et châssis de camion ont été progressivement éliminés entre juillet 2002 et janvier 2001 ; elles avaient été introduites pour des raisons de balance des paiements en 1997.

Si les importations de machines d'occasion, de produits remis à neuf ou de rejets d'usine de toutes sortes sont interdites, certains biens d'occasion ou usagés non fabriqués localement peuvent être importés, sous réserve de certaines conditions ${ }^{50}$; les importations de machines d'occasion admissibles sont néanmoins soumises à une inspection avant expédition pour vérifier que leur durée de vie utile est raisonnable. Deux produits (déchets plastiques, avertisseurs à pression) ont été inscrits à la liste des interdictions pour des motifs environnementaux.

\section{Papouasie Nouvelle-Guinée (1999)}

Selon les autorités, le pays n'impose plus d'interdictions ou de contingents d'importation. Ceux-ci avaient auparavant pour objectif d'encourager les industries manufacturières nationales (bœuf en boîte, sucre, ciment, légumes, farine, piles et maquereau en boîte). Ils ont été supprimés, pour la plupart avant 1996, et

\footnotetext{
${ }^{49}$ Conformément au règlement realtif aux CFS et aux halons du 21 janvier 1991 et à celui relatif au tétrachlorure de carbone et au méthyl chloroforme du 28 mars 1995.

50 Autres exceptions: livres, magazines, revues, vêtements (dont les chaussures, les tapis de voyage et les couvertures) usagés, certains déchets, les articles de second choix et les chutes de fer et d'acier, l'acier inoxydable, les feuilles et les assiettes d'étain et les ferrailles relaminables.
} 
remplacés par des droits de douane protecteurs et prohibitifs, compris pour l'essentiel entre $30 \%$ et $80 \%$, voire plus. Par souci de protection de l'environnement, les autorités interdisent l'importation de certains pesticides destinés à l'agriculture, à savoir le DDT, le chlordane, le dieldrine et l'endrine.

En tant que partie au Protocole de Montréal relatif à des substances qui appauvrissent la couche d'ozone, le pays interdit aussi les importations de CFC et d'autres substances qui appauvrissent la couche d'ozone. Il est aussi signataire de la Convention de Bâle sur le contrôle des mouvements transfrontières de déchets dangereux et de leur élimination. Les restrictions aux importations s'appliquent à la faune et à la flore sauvages en vertu de la Convention sur le commerce international des espèces de faune et de flore sauvages menacées d'extinction (CITES). Elles sont inscrites dans la loi sur le commerce international (faune et flore) de 1979.

\section{Pérou (2000)}

Les interdictions sont motivées par des considérations relatives à la protection de la santé et de l'environnement, les seules exceptions étant celle visant les textes géographiques ou les cartes qui tronquent le territoire national (identité nationale) et les boissons alcooliques étrangères portant le nom de Pisco (dénomination d'origine protégée).

\section{Philippines (1999)}

Les autorités ont noté que le programme de libéralisation des importations a éliminé la plupart des mesures non tarifaires autre que celles maintenues pour des motifs de santé, de sûreté et de sécurité nationale. Depuis le précédent Examen des politiques commerciales, en 1993, diverses restrictions ont été levées : les restrictions à des fins de balance des paiements sur le charbon et les produits du charbon en vigueur au début de 1999 semblent avoir été supprimées ; leur libéralisation avait été prévue pour la fin de 1997.

Les Philippines ont renoncé à se prévaloir de l'article XVIII:B compte tenu de la libéralisation des dernières restrictions aux fins de balance des paiements avant le 31 décembre 1997. En 1995, les restrictions d'importation sur les nouveaux véhicules automobiles et sur certains camions et autobus usagés ont été levées.

\section{Roumanie (1999)}

Interdictions appliquées aux importations et exportations aux fins de protection de la moralité publique, de la santé, de la vie humaine, de l'environnement et de la sécurité nationale. Le mécanisme de réglementation des importations s'applique actuellement aux produits suivants : les armes et munitions; le matériel militaire, les pièces détachées et toute documentation technique utilisée pour fabriquer ce type de produits, ; la ferraille et d'autres déchets dangereux pour la santé humaine, notamment les stupéfiants et narcotiques, ou pour l'environnement ; les marchandises assujetties au contrôle de la destination finale, pour des raisons associées à la non-prolifération d'armes de destruction massive et de plates-formes lancemissiles, ainsi que les matériaux radioactifs, les installations nucléaires et les produits associés au nucléaire.

\section{Sénégal (2003)}

Interdictions sur l'importation d'armes et de munitions, d'explosifs, de diamants bruts non clivés ou taillés, de stupéfiants et narcotiques, et de publications obscènes. L'interdiction d'importation de certains véhicules d'occasion a été levée en 1996.

\section{Singapour (2000)}

Interdictions aux fins de santé et de sécurité publiques, de protection de l'environnement, de sécurité nationale, et conformément aux accords internationaux et aux résolutions du Conseil de sécurité des Nations Unies.

De nouvelles interdictions ont été instaurées sur le matériel de télécommunications contrôlé, notamment les récepteurs à exploration, l'équipement de communications militaires et les cosmétiques contenant des substances ou des additifs prohibés dans des proportions supérieures aux limites fixées. 
Afrique du Sud (2003)

L'importation de certaines marchandises usagées est prohibée. Interdictions d'importation de déchets et de matériaux dangereux. L'importation de certains pesticides (aldrine, dieldrine, composés de mercure et certains mélanges d'isomère) est interdite, celles de certains autres (composés d'arsenic inorganiques, chlordane, DDT) étant rigoureusement limitée.

\section{Sri Lanka (2004)}

Des interdictions sont maintenues pour des raisons de santé, de sûreté, de sécurité, d'environnement et de moralité. En 2004, l'âge limite pour l'importation de machines de construction usagées a été ramené de 10 à 7 ans.

\section{Suisse (2000)}

Des interdictions s'appliquent en vertu des conventions internationales et pour des raisons de santé publique et de sécurité (substances chimiques toxiques, armes $\mathrm{ABC}$ et mines antipersonnel).

En vertu de l'ordonnance sur les substances dangereuses pour l'environnement, la fabrication, la fourniture, l'importation et l'utilisation de certaines substances chimiques sont également interdites pour des motifs de protection environnementale et/ou des considérations de santé et de sécurité publiques. Il s'agit des produits suivants : hexachlorocyclohexane, aldrine, dieldrine, endrine, heptachlore et époxyde d'heptachlore, isodrine, kélévane, chlordécone, télodrine, strobane, toxaphène, hexachlorobenzène, biphényles, terphényles, naphtalines et diarylalkanes halogénés, DDT, 2,4,5-trichlorophénols et PCP.

\section{Tanzanie (2000)}

Les restrictions actuellement en vigueur sont maintenues pour des raisons de santé, de sécurité ou de moralité, et concernent des produits tels que les armes et munitions, les explosifs, le matériel militaire et les substances narcotiques.

\section{Thaïlande (2003, 1999)}

Des interdictions sur les importations sont en vigueur aux fins de protection de la moralité publique, de la sécurité nationale, de la vie humaine, animale ou végétale et de la santé. Elles couvrent également les imitations frauduleuses et le matériel destiné à leur fabrication, et le marbre.

L'importation de pierres monumentales ouvrées ou de construction est prohibée à des fins de protection de l'industrie ; celle des sacs de jute ou d'autres textiles, pour garantir le revenu des agriculteurs ; celles des motocyclettes usagées et de leurs moteurs pour des raisons de santé et de sécurité publiques; les réfrigérateurs ménagers utilisant des CFC dans le processus de production, et les produits céramiques émaillés. Les automobiles et moteurs nouveaux sont assujettis à un régime de licences, mais interdits dans la pratique.

Togo (1999)

Le démantèlement des restrictions quantitatives, des licences ou des interdictions sur les importations, engagé en 1989 dans le cadre de programmes d'ajustement structurel, a été mené à terme en 1995 avec l'abolition des dernières de ces mesures sur la farine de blé, le ciment, les barres pour béton armé et les tôles galvanisées.

Les restrictions actuellement en vigueur sont maintenues pour des raisons de santé, de sécurité ou de moralité, et concernent des produits tels que les armes et munitions, les explosifs et le matériel militaire, les substances narcotiques et certains produits pharmaceutiques (psychotropes par exemple). 
États-unis d'Amérique (2004, 2001, 1999)

Interdictions visant à garantir la sécurité nationale, sauvegarder la santé des consommateurs, protéger la moralité publique ou à des fins de protection de l'environnement. Des restrictions sur l'importation d'uranium, du nitrate d'ammonium et de produits sidérurgiques ont été négociées avec la Russie, et sur celle de silico-manganèse et de produits sidérurgiques avec l'Ukraine.

Des restrictions quantitatives s'appliquent aux importations de divers produits sidérurgiques, conformément à l'accord de suspension conclu à la suite d'enquêtes anti-dumping avec la Russie, la Chine et le Brésil.

Le commerce des textiles et des vêtements reste assujetti à des contingents d'importation appliqués aux importations de certains produits en provenance de plus de 40 pays.

Les marchandises dont il peut être prouvé qu'elles ont été extraites, produites ou fabriquées totalement ou en partie dans un pays étranger par un travail asservi, industrialisé, esclave ou forcé ne peuvent entrer aux États-Unis.

Tout animal ou oiseau sauvage, s'il est capturé ou exporté en infraction à la loi du pays étranger; les plumes ou la peau de tout oiseau sauvage, sauf à des fins scientifiques et éducatives; les articles immoraux; le bétail, les ovins, les porcins et les viandes de tout pays pour lequel le Secrétaire de l'agriculture a établi l'existence de peste bovine ou de fièvre aphteuse. Afin d'appliquer la Convention internationale pour la conservation des thonidés de l'Atlantique (ICCAT), les importations de thon rouge de l'Atlantique et de tous ses produits dérivés pêchés par les navires du Panama, du Honduras et du Belize sont interdites.

\section{Venezuela (2002)}

Interdictions visant à protéger la vie et la santé des personnes et des animaux, à préserver la vie végétale et à protéger la moralité publique, l'environnement et les intérêts essentiels de sécurité du pays.

L'importation d'allumettes est interdite, sauf celles en provenance de certains pays andins. Les véhicules usagés ou les modèles obsolètes pour usage privé, ainsi que les vêtements usés et les pneus d'occasion sont également assujettis à des interdictions d'importation. L'interdiction sur les véhicules usagés a pour objet de jeter les bases réglementaires pour le fonctionnement et le développement de l'industrie automobile nationale. Une exception est faite dans le cas des pneus importés de pays andins.

\section{Zambie (2002)}

Interdictions pour des raisons environnementales et morales et pour des raisons de santé et de sécurité, et en vertu de conventions internationales. Les interdictions d'importation sont les suivantes:: ) les pièces ou les billets de banque faux ou contrefaits, et les pièces ou les billets de banque qui sont destinés à la circulation en Zambie bien qu'ils n'aient pas cours légal en Zambie; ii) les marchandises indécentes, obscènes ou condamnables; iii) les marchandises fabriquées ou produites en totalité ou en partie par une main-d'œuvre carcérale ou à l'intérieur ou dans le cadre d'un établissement carcéral ou pénitentiaire, à l'exclusion des cadeaux faits de bonne foi par un détenu pour l'usage personnel d'une personne de droit privé; iv) les marchandises piratées ou contrefaites et les marchandises portant des marques ou désignations fausses ou trompeuses quant à leur origine, leur objet et leur usage.. 